Spring 2020
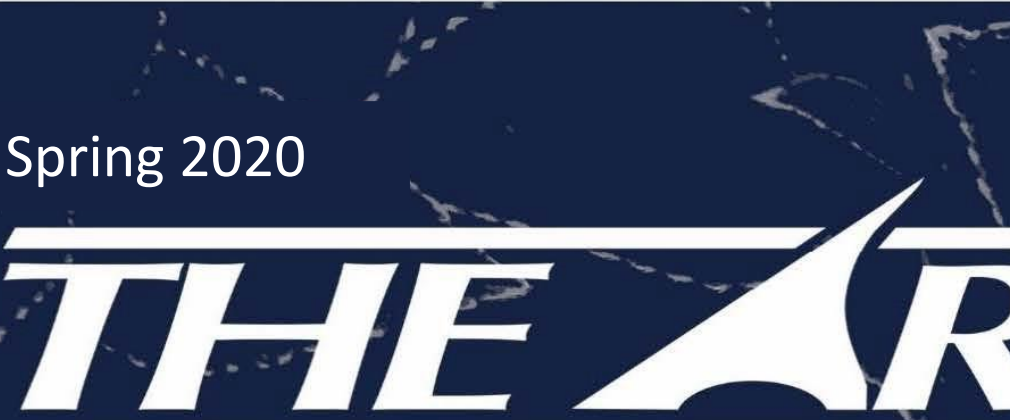

Special Edition Issue Volume 3 Issue 2

Augusta University's Undergraduate Research Journal

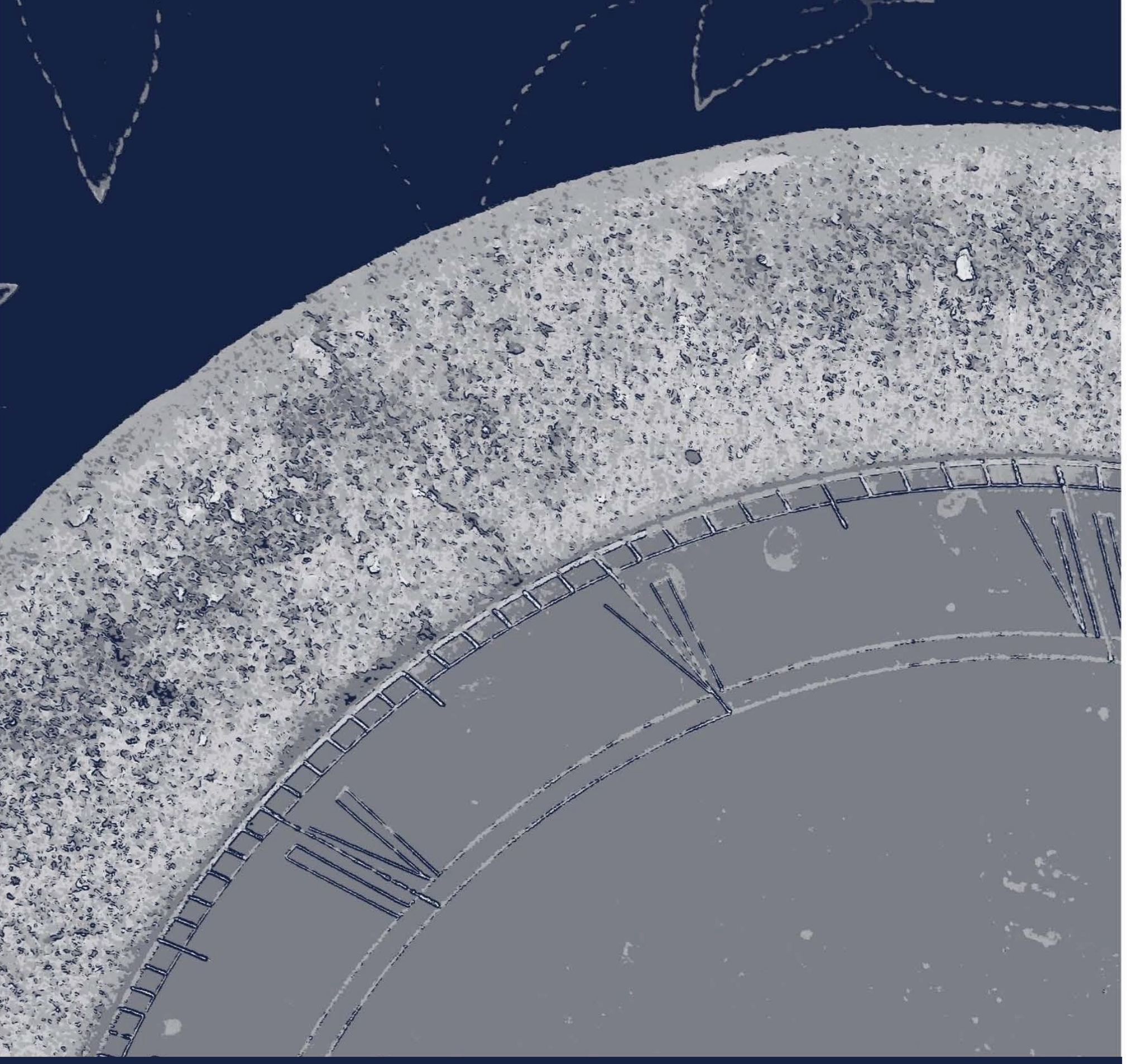

THE HONOR SOCIETY OF 


\begin{abstract}
About The Arsenal
The Arsenal: The Undergraduate Research Journal of Augusta University is a peer-reviewed, open access, interdisciplinary journal for undergraduate research conducted at Augusta University. This journal is managed in collaboration by the Center for Undergraduate Research and Scholarship (CURS), University Libraries, and the student organization On the Shoulder of Giants.

The Arsenal was initiated by On the Shoulder of Giants in Fall 2016. The journal represents and highlights undergraduate research of academic and scholarly value from various disciplines at Augusta University. Each article undergoes a peer-review process facilitated by the journal's Editorial Review Board and must be approved by an appointed faculty reviewer in the article's respective discipline.
\end{abstract}




\section{About The PKP Special Issue}

This special issue of The Arsenal presents the abstracts of the 21st Annual Phi Kappa Phi (PKP) Student Research and Fine Arts Conference, with permission given from the authors and faculty advisors.

The annual PKP Student Research and Fine Arts Conference is an opportunity for all undergraduate students of Augusta University to showcase their scholarly and artistic endeavors, either through an oral presentation or through a poster presentation. Due to COVID-19, this year's PKP Conference was unfortunately cancelled.

More information regarding PKP and the conference can be found on their website: https://www.augusta.edu/honorsocieties/pkp/ 


\section{The Arsenal Faculty Editorial Board}

Quentin Davis, PhD

Center of Undergraduate Research and Scholarship

Jennifer Putnam Davis, MA, MLIS

University Libraries

Melissa Johnson, MLIS, MA

University Libraries

Melissa Knapp, BA

Center of Undergraduate Research

Laurence Miller, PhD

Department of Psychological Sciences

\section{Phi Kappa Phi Conference Committee}

Ruchi Patel, PhD (Co-Chair)

Department of Biological Sciences

Colleen Davis, PhD (Co-Chair)

Department of Biological Sciences

Sandra Bandy, MLS, AHIP

University Libraries

Elizabeth Culatta, PhD

Department of Social Sciences

Trinanjan Datta, PhD

Department of Chemistry and Physics

Quentin Davis, PhD

Center of Undergraduate Research and Scholarship

Jennifer Putnam Davis, MLIS, MA

University Libraries

Melissa Knapp, BA

Center of Undergraduate Research and Scholarship

A.B. Osborne, MFA

Department of Art and Design

Jean Pawl, PhD

Department of Biobehavioral Nursing

Seretha Williams, PhD

Department of English and Foreign Languages 


\section{Table of Contents}

Volume 3, Issue 2 (2020)

Special Edition

\section{EDITORIAL}

i About The Arsenal

ii About PKP Special Issue

iii Editorial Board and PKP Conference Committee Members

\section{RESEARCH ABSTRACTS}

1 A Study of Human Skin Color, A Natural Sunscreen: Physiology, Molecular Evolution, Public Health, and Student Learning Juan Ayala

2 Establishing a GFP Marker in Zebrafish to Study the Localization of Tinagl1 Helena Blackburn

3 How Does Economic Turmoil Affect Alcohol Consumption? Augustus Bruker

4 The Impact of Vegetarians and Vegans on the Meat, Egg, and Dairy Industry Marie Cantenot 
5 Degradation of EGFR Contributes to Anti-Cancer Effects of HDAC Inhibitor in Head and Neck Cancer

Leslie Duncan, Caleb Jensen, Leilei He, and Liwei Lang

6 Early Extubation in Infancy and Early Childhood Following Heart Surgery: Outcome Analysis and Predictors of Failures

Raquel Esquivel, Emma Geister, Danielle Crethers, Danalynn Weatherholt, Maria Gabriela Sanchez, and Gustavo Munoz

7 "Illegal": Job Attainment and Socio-Economic Status Among First-Generation Mexican Americans, 1980s-2000s

Isabella Esteban

8 Diagnosis of Mental Illness in the Narrator of Charlotte Perkin Gilman's

"The Yellow Wallpaper" Using the DSM-5

Wayne Fang

9 Using Machine Learning to Predict the Critical Reynolds Number of a Tandem Cylinder System Ivan A. Florentino

10 CBD Analysis in Oils and Foods Joanna Foley

11 Perfluorooctanoic Acid (in the Presence of Fetal Bovine Seruym) Induces Proliferation in ER $\alpha$ Positive and ER $\alpha$ Negative Breast Cancer Cell Lines

Victoria Gaw and Manderrious Glenn

12 Fast-Track Extubation in Infancy and Early Childhood Following Heart Surgery: Outcome Analysis and Predictors of Failure

Emma Geister, Raquel Esquivel, Danielle Crethers, Danalynn Weatherholt, Maria Gabriela Sanchez, and Gustavo Munoz

13 Schizoaffective Disorder Depressive Type in "The Yellow Wallpaper" by Charlotte Perkins Gilman Lindsey German

14 Development of an Alternative Energy Envelopment of an Alternative Energy Synthetic Pathway to Nylon 6,6 Through the Use of Solar Irradiation as the Sole Heat Source Caroline Hammond

15 Prehistoric Dinosaurs: An Exploration of Fact vs. Fiction Through the Creation of Comparative Sculptural Forms

Krista Havens 
16 The Detection and Prevalence of Microsporidia in Shrimp from the Satilla River Estuary Miranda Henderson and Jenelly Canela

17 Evaluation of Mammal Hair as a Potential Wild Pig Repellent on Cowden Plantation in Jackson, South Carolina

Samantha R. Hitchens

18 Mindfulness Meditation through a Mobile App

Sabrina Huff, Cleston-Lee Murray, Leigha Restrepo, and Shelby Jones

19 Implementing the Healthy University Approach to Mental Health at Augusta University Lauren Jackson

20 ATAD3A: A Critical Driver for Head and Neck Cancer

Caleb Jensen and Liwei Lang

21 Competitive Balance in Women's Collegiate Golf

Austin Jones

22 Assessing Students' Spatial Abilities in Neuroanatomy Education

Arundhati Kumar and Tasha R. Wyatt

23 Ionic and Covalent Conjugates of Metronidazole and Tryptamine

Dominique Lyons and Precious Baako

24 Impacts of Cultural Barriers on Healthcare

Eden Mahoney

25 Can Fast Fashion Be Sustainable and Still Be Profitable?

Eva Miralles Miro

26 Characterization of Protein Sensitive G-Protein Coupled Receptors

Alisha Nam, Najeah Okashah, and Nevin Lambert

27 LGBTQ+ College Students' Well-being and Physical Activity

Dalanie Nix

28 Diabetes Attenuation of the Estrogen-Mediated Increase in Endothelial Function is Associated with Circulating SIRT1

Sinead O’Bryant, Casey Derella, Jeff Thomas, Jacob Looney, and Marie-Rose Bieck

29 Developmental Biology of Zebrafish and Integration of Transgenic Lines to Study Microglia in Perspective of Glioblastoma

Anabelle O'Keefe, Katherine McCartney, and Umasai Kandepu 
30 Unconsciously in the Closet: Repressed Queerness in Another Country

Anabelle O'Keefe

31 Minimum Flow Rate in Electro-Coflow

Benjamin Overlie

32 The Evolution of Art Therapy and Proposed Future Application

Connor Owen

33 The Application of Low-Cost, Close-Range Photogrammetry in Dentistry

Mohit Patel and D. Mettenburg

34 Salty or Slightly Salty: Is Fish Species Richness Affected by an Obsolete Navigational Cut?

Rebecca Patterson, Loren Mathews, and Bruce Saul

35 Stress Coping Mechanism and the Effects of Academic Stress

Erin Quick

36 Delusional Disorder in the Narrator of Maud

Havilah Ravula

37 Feasibility of Reusable Radiochromic Plastics as Dosimeter

Maxwell Recht, Chase Inglett, Joseph Hauger, and John Adamovics

38 Investigating Signaling Pathways Involving the HCA Receptor Family

Dalia Saj, Najeah Okashah, and Nevin Lambert

39 Assessing Local Parks for their Infrastructure, Issues, and Use

Elizabath Shabu

40 Development of Defined Culture Conditions for Human Wharton's Jelly Stem Cells Arika Shaikh

41 Portrayal of Mental Illness in Edgar Allan Poe's "The Tell-Tale Heart" Arika Shaikh

42 The Spaces They Occupied: Women as the Determiners of Success in the French Revolution Keturah Stewart

43 Design, Synthesis, and Computational Studies of Isoniazid Hybrid Conjugates as Potential Antimycobacterial Agents

Eyana Thomas 
44 The Impact of Cardiac Rehabilitation on CVD Risk Factors in Diabetic Patients Eyana Thomas, Eric Lian, and Kimberly Roberts

45 Curcumin Conjugates as Potential Therapeutics for Breast Cancer Queen Tran

46 The Past is a Foreign Country They View Things Differently There: The Perception of "The Invisible Empire of the Ku Klux Klan" as a Benevolent Secret Society from 1915 to 1965 Dillon Typhair

$47 \quad$ Give Rise

Rachel M. Visintainer

48 Design and Synthesis of Selective COX-2 Inhibitors as Potential Anti-Inflammatory Agents Margaret Wade

49 How Does Industrial Concentration Prepare an Economy for Business Cycle Change? Aaron Walker

50 Atypical Magnesium Requirements in a Phyllite Population of Rare Plant Species, Pediomelum Piedmontatum

Matthew Zimmerman 


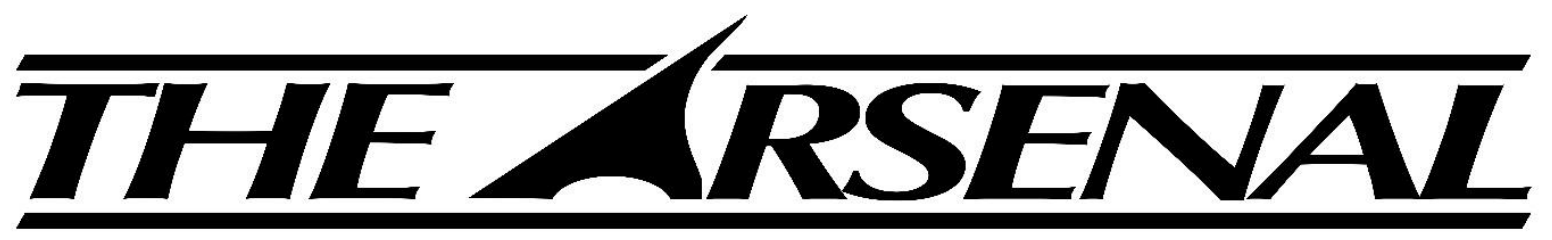

\section{Augusta University's Undergraduate Research Journal}

ISSN 2380-5064 | The Arsenal is published by the Augusta University Libraries | http://guides.augusta.edu/arsenal

Volume 3, Issue 2 (2020)

Special Edition Issue

\section{A STUDY OF HUMAN SKIN COLOR, A NATURAL SUNSCREEN: PHYSIOLOGY, MOLECULAR EVOLUTION, PUBLIC HEALTH, AND STUDENT LEARNING}

Juan Ayala and Soma Mukhopadhyay

\section{Citation}

Ayala, J., \& Mukhopadhyay, S. (2020). A study of human skin color, a natural sunscreen: Physiology, molecular evolution, public health, and student learning. The Arsenal: The Undergraduate Research Journal of Augusta University, 3(2), http://doi.org/10.21633/issn.2380.5064/s.2020.03.02.01

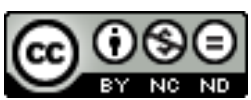

(C) Ayala and Mukhopadhyay 2020. This open access article is distributed under a Creative Commons Attribution NonCommercial-NoDerivs 2.0 Generic License (https://creativecommons.org/licenses/by-nc-nd/2.0/). 


\title{
A Study of Human Skin Color, a Natural Sunscreen: Physiology, Molecular Evolution, Public Health, and Student Learning
}

Presenter: Juan Ayala (Poster Presentation)

Authors: Juan Ayala and Soma Mukhopadhyay

Faculty Sponsor(s): Soma Mukhopadhyay, $\mathrm{PhD}$

Department Affiliation: Biological Sciences

\begin{abstract}
Human skin coloration is a combination of pigmentation, ultraviolet (UV) exposure, gene expression and natural selection. Skin tone is also associated with several physiological processes, such as vitamin D synthesization, calcium homeostasis, maintaining proper blood folate concentration, and the production of serotonin. In recent years, the study of molecular evolution has become very significant not only to understand the human body but also becoming an integral part for understanding public health and other fields of medical science. Our goal of this project was to create an interactive course module for Anatomy and Physiology students to show how skin physiology was driven by evolutionary pressures. The module was also intended to show how exposure to some UV radiation is important for certain biological processes and for offering protection against cancer, as well as how, on the other hand, overexposure might cause damage and lead to cancer. Students were introduced to molecular evolution of skin color and the production of different pigments, eumelanin and pheomelanin to shield DNA from harmful UV light. Additionally, UVAB and UVC irradiance were measured and compared to the UV index which indicates the strength of UV radiation for the day to make people aware of the environmental factors around.
\end{abstract}

Received: 01/31/2020 Accepted: 02/17/2020

Correspondence: Juan Ayala, Augusta University, $112015^{\text {th }}$ St. Augusta, GA 30912, jayala@augusta.edu 


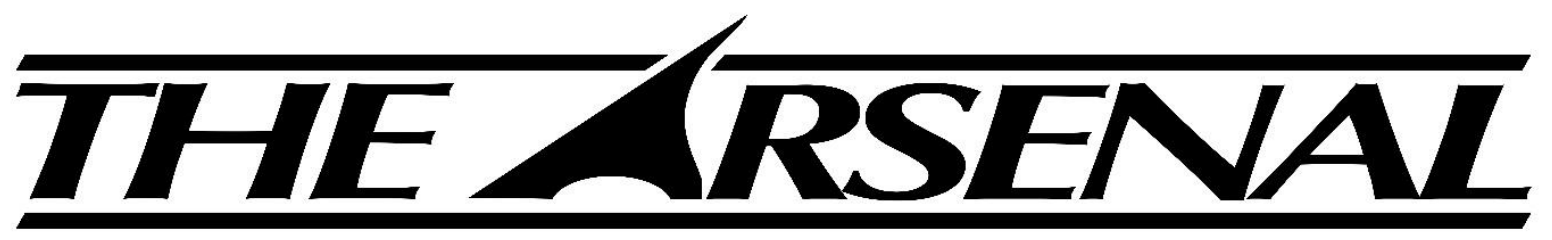

\section{Augusta University's Undergraduate Research Journal}

ISSN 2380-5064 | The Arsenal is published by the Augusta University Libraries | http://guides.augusta.edu/arsenal

Volume 3, Issue 2 (2020)

Special Edition Issue

\section{ESTABLISHING A GFP MARKER IN ZEBRAFISH TO STUDY THE LOCALIZATION OF TINAGL1}

Helena Blackburn and Ellen LeMosy

\section{Citation}

Blackburn, H., \& LeMosy, E. (2020). Establishing a GFP marker in zebrafish to study the localization of Tinagl1. The Arsenal: The Undergraduate Research Journal of Augusta University, 3(2), http://doi.org/10.21633/issn.2380.5064/s.2020.03.02.02 


\section{Establishing a GFP Marker in Zebrafish to Study the Localization of Tinagl1}

Presenter: Helena Blackburn (Poster Presentation)

Authors: Helena Blackburn ${ }^{1}$ and Ellen LeMosy ${ }^{2}$

Faculty Sponsor(s): Ellen LeMosy, MD, PhD

Department Affiliation: ${ }^{1}$ Biological Sciences, ${ }^{2}$ Cellular Biology and Anatomy

Funding: NIAMS, Vanguard Charitable Gifts Fund

\section{ABSTRACT}

Tinagl1 is a secreted protein found in the basement membrane under epithelial cells. The LeMosy Lab previously showed that tinagl1 knockdowns resulted in abnormal spinal development and heart orientation during zebrafish development. These data, together with changes in length of motile cilia, suggested that tinagl1 is involved in cilia function during development. The mechanism of this interaction is unknown, and it is unclear whether tinagl1 is only in basement membranes at the basal side of cells or if it also localizes to the apical side of cells where most cilia project. A deeper understanding of the localization of tinagl1 during development is a logical next step in understanding how this protein functions. Zebrafish provide an excellent model for studying this localization because they display strong phenotypic effects that can be easily imaged. The localization of tinagl1 will be tracked using a tinagl1-GFP fusion construct developed through PCR and insertion into a Tol 2 transposon vector. This construct will be injected into early embryos together with transposase mRNA to create mosaic fish showing tinagl1-GFP in selected tissues. Successful germline integration of the tinagl1-GFP DNA will lead to the development of a transgenic line of zebrafish allowing imaging of tinagl1 localization during development. 


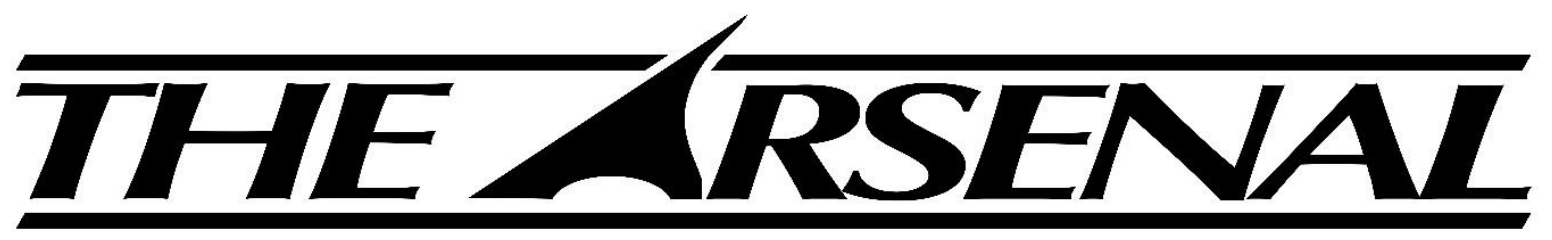

\section{Augusta University's Undergraduate Research Journal}

ISSN 2380-5064 | The Arsenal is published by the Augusta University Libraries | http://guides.augusta.edu/arsenal

Volume 3, Issue 2 (2020)

Special Edition Issue

\section{HOW DOES ECONOMIC TURMOIL AFFECT ALCOHOL CONSUMPTION?}

Augustus Bruker and Simon Medcalfe

\section{Citation}

Bruker, A., \& Medcalfe, S. (2020). How does economic turmoil affect alcohol consumption? The Arsenal: The Undergraduate Research Journal of Augusta

University, 3(2), http://doi.org/10.21633/issn.2380.5064/s.2020.03.02.03 


\title{
How Does Economic Turmoil Affect Alcohol Consumption?
}

Presenter: Augustus Bruker (Poster Presentation)

Authors: Augustus Bruker and Simon Medcalfe

Faculty Sponsor(s): Simon Medcalfe, $\mathrm{PhD}$

Department Affiliation: Business

Funding: Augusta University CURS Student Research Grant

\begin{abstract}
This presentation's purpose is to examine the affects that recessive economic periods have on drinking habits in different countries. A recession is a very complex economic event that can affect behavioral patterns, including changes in drinking habits, across countries. The economic factors studied will include changes in median household incomes, unemployment rates, and gross domestic products (GDP) of different countries. Alcohol consumption will be broken down into beer, wine, and spirits, which is necessary to the research because different countries may show different trends in what form of alcohol they choose to turn to during a recession. This research is important because it could potentially show a global problem in which society is turning to the dangerous habit of alcoholism to deal with their economic hardships. For the data in my paper, I plan to refer to the World Health Organization's 2018 global status report on alcohol and health. This report has data for all major countries pertaining to how much alcohol they consume per year on average, what types of alcohol the country prefers, and how factors such as age, gender, and race affect drinking in their country. I hypothesize that the public does in fact drink more alcohol during times of economic turmoil.
\end{abstract}

Received: 01/31/2020 Accepted: 02/17/2020

Correspondence: Augustus Bruker, Augusta University, $112015^{\text {th }}$ St. Augusta, GA 30912, aubruker@augusta.edu 


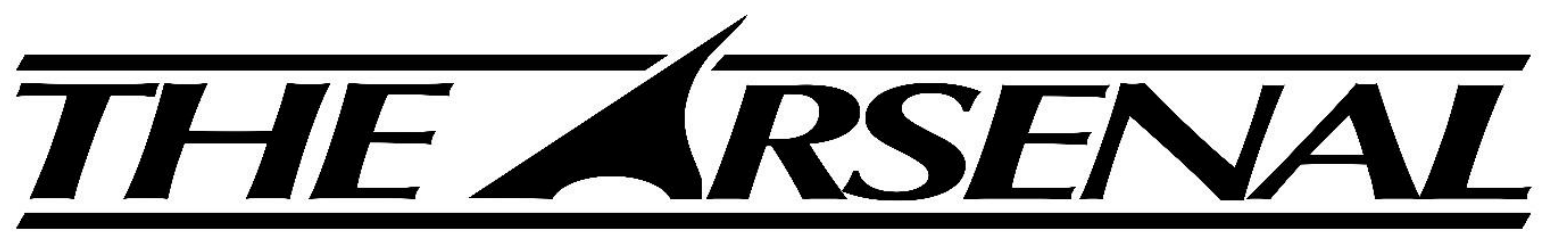

\section{Augusta University's Undergraduate Research Journal}

ISSN 2380-5064 | The Arsenal is published by the Augusta University Libraries | http://guides.augusta.edu/arsenal

Volume 3, Issue 2 (2020)

Special Edition Issue

\section{THE IMPACT OF VEGETARIANS AND VEGANS ON THE MEAT, EGG, AND DAIRY INDUSTRY}

Marie Cantenot and Simon Medcalfe

\section{Citation}

Cantenot, M., \& Medcalfe, S. (2020). The impact of vegetarians and vegans on the meat, egg, and dairy industry. The Arsenal: The Undergraduate Research Journal of Augusta University, 3(2), http://doi.org/10.21633/issn.2380.5064/s.2020.03.02.04 


\title{
The Impact of Vegetarians and Vegans on the Meat, Egg, and Dairy Industry
}

Presenter: Marie Cantenot (Poster Presentation)

Authors: Marie Cantenot and Simon Medcalfe

Faculty Sponsor(s): Simon Medcalfe, $\mathrm{PhD}$

Department Affiliation: Business

\begin{abstract}
People cut meat out of their diet for three reasons: health, environmental, and animal suffering. Some even go as far as following a vegan diet, a type of vegetarian diet that excludes meat, eggs, dairy, and all other animal-derived products. Many vegetarian and vegan groups believe the production of meat is unethical and unsustainable, and therefore aim to abolish the industry through the boycott of all animal products. This raises the question of how this lifestyle may have a true impact on meat, eggs, and dairy prices. This research aims to explore the interrelationship between the rise of vegetarianism and veganism and the changes in beef, pork, chicken, eggs, and dairy prices. The data will be the monthly percentage of vegetarians/vegans in the U.S. and the prices for beef, poultry and pork, and eggs and dairy from January 2014 until May 2018, controlling for other factors that affect these prices. The results from a regression analysis will show whether the increasing number of vegetarians and vegans has an impact on the prices offered by the meat, egg, and dairy industry.
\end{abstract}




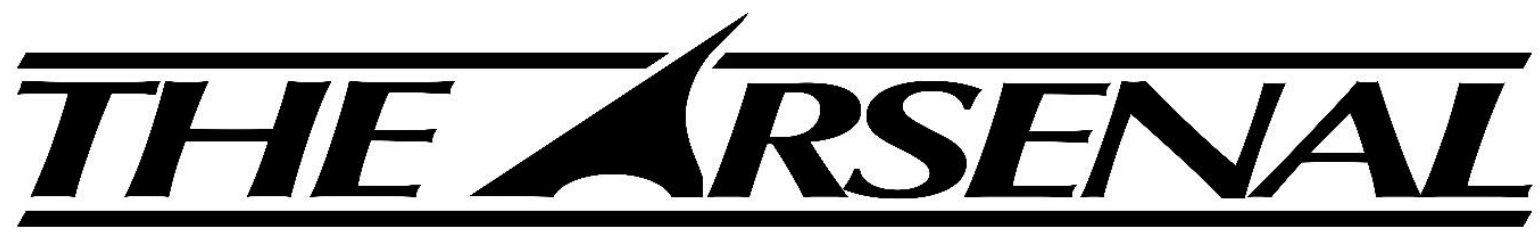

Augusta University's Undergraduate Research Journal

ISSN 2380-5064 | The Arsenal is published by the Augusta University Libraries | http://guides.augusta.edu/arsenal

Volume 3, Issue 2 (2020)

Special Edition Issue

DEGRADATION OF EGFR CONTRIBUTES TO

ANTI-CANCER EFFECTS OF HDAC INHIBITOR IN

HEAD AND NECK CANCER

Leslie Duncan, Caleb Jensen, Leilei He, Liwei Lang, and

Yong Teng

\section{Citation}

Duncan, L., Jensen, C., He, L., Lang, L., \& Teng, Y. (2020). Degradation of EGFR contributes to anti-cancer effects of HDAC inhibitor in head and neck cancer.

The Arsenal: The Undergraduate Research Journal of Augusta University, 3(2), http://doi.org/10.21633/issn.2380.5064/s.2020.03.02.05 


\section{Degradation of EGFR Contributes to Anti-Cancer Effects of HDAC Inhibitor in Head and Neck Cancer}

Presenter: Leslie Duncan (Poster Presentation)

Authors: Leslie Duncan ${ }^{1}$, Caleb Jensen ${ }^{1}$, Leilei $\mathrm{He}^{2}$, Liwei Lang ${ }^{2}$, and Yong Teng ${ }^{2,3}$

Faculty Sponsor(s): Yong Teng, $\mathrm{PhD}$

Department Affiliation: ${ }^{1}$ Biological Sciences, ${ }^{2}$ Oral Biology \& Diagnostic Sciences, ${ }^{3}$ Georgia Cancer Center

Funding: Augusta University Provost's Office and the Translational Research Program of the Department of Medicine

\section{ABSTRACT}

A promising arsenal of histone deacetylase (HDAC)-targeted treatment has emerged in the past decade. The abnormal targeting or retention of HDACs to DNA regulatory regions often occurs in many cancers, including head and neck squamous cell carcinoma (HNSCC); however, few cancers have been studied regarding the beneficial role of HDAC inhibition in anti-HNSCC therapy, and the underlying molecular mechanisms remain elusive. Epidermal growth factor receptor (EGFR) is commonly expressed at high levels in HNSCC (more than 90\%) and serves as a prime target for new anti-HNSCC therapy. Interestingly, Trichostatin A (TSA), one of HDAC inhibitors, not only inhibits EGFR phosphorylation, but also induces repression of EGFR total protein amount in HNSCC cells. We further show that TSA induces EGFR degradation through the ubiquitinproteasome pathway in HNSCC cells, which is associated with downregulated AKT and ERK1/2 signaling pathways. The study uncovers that EGFR is one of targets of HDACbased treatment, providing mechanistic insight into the action of HDAC inhibitors. As there is an increasing interest in using HDAC inhibitors for cancer treatment in clinics, the outcomes from the present study would be significantly beneficial for the development of new rational HDAC-targeted anticancer modalities.

Received: 01/31/2020 Accepted: 02/17/2020

Correspondence: Leslie Duncan, Augusta University, $112015^{\text {th }}$ St. Augusta, GA 30912, leduncan@augusta.edu 


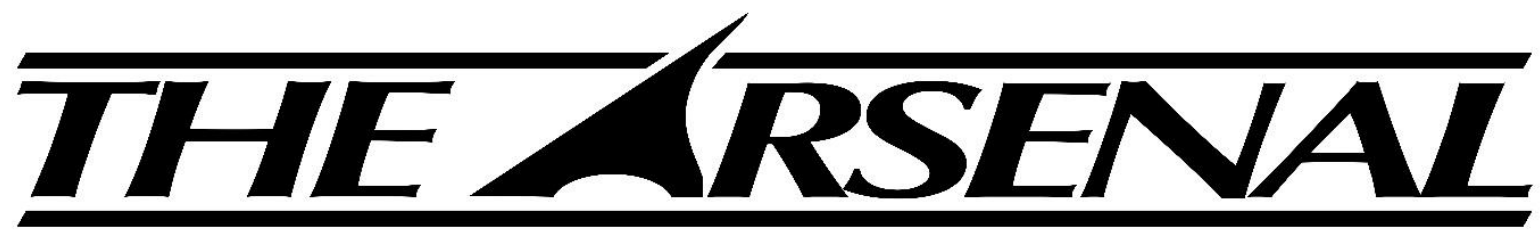

Augusta University's Undergraduate Research Journal

ISSN 2380-5064 | The Arsenal is published by the Augusta University Libraries | http://guides.augusta.edu/arsenal

Volume 3, Issue 2 (2020)

Special Edition Issue

EARLY EXTUBATION IN INFANCY AND EARLY

CHILDHOOD FOLLOWING HEART SURGERY:

OUTCOME ANALYSIS AND PREDICTORS OF FAILURES

Raquel Esquivel, Emma Geister, Danielle Crethers, Danalynn

Weatherholt, Maria Gabriela Sanchez, Gustavo Munoz, and

Anastasios C. Polimenakos

\section{Citation}

Esquivel, R., Geister, E., Crethers, D., Weatherholt, D., Sanchez, M. G., Munoz, G.

\& Polimenakos, A. C. (2020). Early extubation in infancy and early childhood

following heart surgery: Outcome analysis and predictors of failures. The Arsenal:

The Undergraduate Research Journal of Augusta University, 3(2),

http://doi.org/10.21633/issn.2380.5064/s.2020.03.02.06

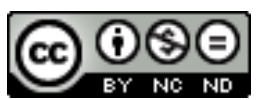

(C) Esquivel et al. 2020. This open access article is distributed under a Creative Commons Attribution NonCommercial-NoDerivs 2.0 Generic License (https://creativecommons.org/licenses/by-nc-nd/2.0/). 


\section{Early Extubation in Infancy and Early Childhood Following Heart Surgery: Outcome Analysis and Predictors of Failure}

Presenter: Raquel Esquivel (Poster Presentation)

Authors: Raquel Esquivel ${ }^{1}$, Emma Geister ${ }^{1}$, Danielle Crethers ${ }^{2}$, Danalynn Weatherholt ${ }^{2}$, Maria Gabriela Sanchez ${ }^{2}$, Gustavo Munoz ${ }^{2}$, and Anastasios C. Polimenakos ${ }^{2}$

Faculty Sponsor(s): Anastasios C. Polimenakos, MD

Department Affiliation: ${ }^{1}$ Biological Sciences, ${ }^{2}$ Medical College of Georgia

Funding: Augusta University CURS Summer Scholars Program

\section{ABSTRACT}

Fast-track (FT) strategies and early extubation (EE), when feasible, can have beneficial effects on clinical outcomes. Despite positive findings in adult cardiac surgery studies, EE procedures have not been rigorously evaluated in the pediatric cardiac populations. We sought to determine feasibility and clinical outcomes of EE in infancy and early childhood following congenital heart surgery (CHS), as well as to identify predictors of failure and highlight cost implications related to FT. A retrospective chart review of children $\leq 6$ years old who underwent CHS at the Children's Hospital of Georgia from January-December 2017 was performed. EE was defined as successful removal of the endotracheal tube in the operating room or upon arrival in intensive care unit (ICU). Multivariate analysis was used to compare peri-operative data, identify the predictors of EE failure, and assess total hospital cost. Of the 64 patients reviewed, mean hospital length of stay (LOS) was 6.97+/4.1 days in EE compared to $21.78+/-13.45$ days in non-EE ( $p<0.0001)$. There was a near 3-fold cost increase failing EE/fast track which impacted total hospital cost for EE compared to non-EE patients ( $\mathrm{p}<0.0001$, mean: $\$ 51419.913 \mathrm{sd}=23,196.203$ ). Deployment of FT strategy with EE is safe and feasible following CHS during infancy and early childhood. Proper customization and implementation, through patient modifiable variables, can have powerful impact on cost-containment.

Received: 01/31/2020 Accepted: 02/17/2020

Correspondence: Raquel Esquivel, Augusta University, $112015^{\text {th }}$ St. Augusta, GA 30912, $\underline{\text { resquivel@augusta.edu }}$ 


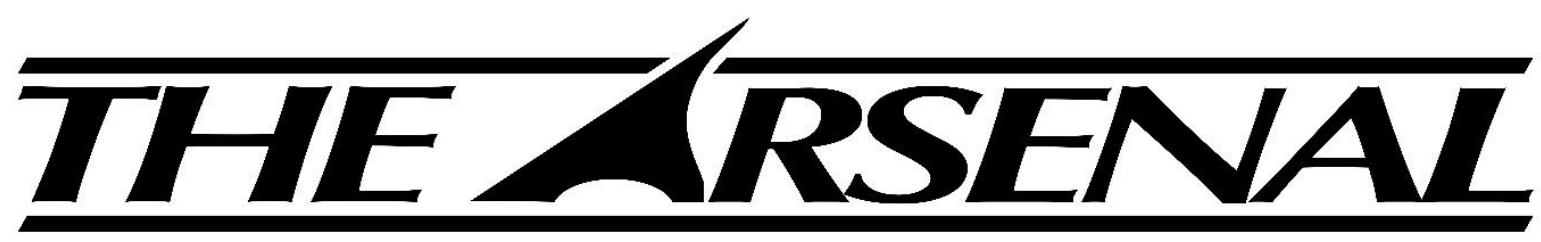

\section{Augusta University's Undergraduate Research Journal}

ISSN 2380-5064 | The Arsenal is published by the Augusta University Libraries | http://guides.augusta.edu/arsenal

Volume 3, Issue 2 (2020)

Special Edition Issue

\section{"ILLEGAL": JOB ATTAINMENT AND SOCIO-ECONIMIC STATUS AMONG FIRST-GENERATION MEXICAN AMERICANS, 1980s-2000s}

Isabella Esteban and Heather Chiero

\section{Citation}

Esteban, I., \& Chiero, H. (2020). "Illegal": Job attainment and socio-economic

status among first-generation Mexican Americans, 1980s-2000s. The Arsenal:

The Undergraduate Research Journal of Augusta University, 3(2), http://doi.org/10.21633/issn.2380.5064/s.2020.03.02.07 


\section{"Illegal": Job Attainment and Socio-Economic Status Among First-Generation Mexican Americans, 1980s-2000s}

Presenter: Isabella Esteban (Oral Presentation)

Authors: Isabella Esteban ${ }^{1}$ and Heather Chiero $^{2}$

Faculty Sponsor(s): Heather Chiero, $\mathrm{PhD}$

Department Affiliation: ${ }^{1}$ Chemistry and Physics, ${ }^{2}$ History, Anthropology, and Philosophy

\section{ABSTRACT}

Between the 1980s to 2000s, Mexican Americans greatly transformed American society by leaving an imprint on culture, education, and the workforce that continues to resonate today. However, their successes did not come easy as they were challenged with numerous stereotypes, which, in turn, effected the jobs they received and their socio-economic status within society overall. Upon immigrating into the United States, first-generation Mexican Americans struggle with finding stable jobs as their illegal status carried a negative connotation that was influenced by the increase of Hispanic gang violence in the 1980s. Even today, a Mexican American living in the United States may face a limited job market affecting their socio-economic status due to said negative stereotypes. This study seeks to examine the stereotypes experienced by Mexican Americans particularly in the Southwest of the Unites States, and how said stereotypes affect their job access and their economic stability. These stereotypes that are common in society will be examined through films and media to determine how these forms of art are used to influence or combat stereotypes. Taking a closer look at these stereotypes and their impact on Mexican Americans will consequently allow others to better understand the impact of news media and entertainment on current politics, policies and economic disparities in the Latino community.

Received: 01/31/2020 Accepted: 02/17/2020

Correspondence: Isabella Esteban, Augusta University, $112015^{\text {th }}$ St. Augusta, GA 30912, iesteban@augusta.edu 


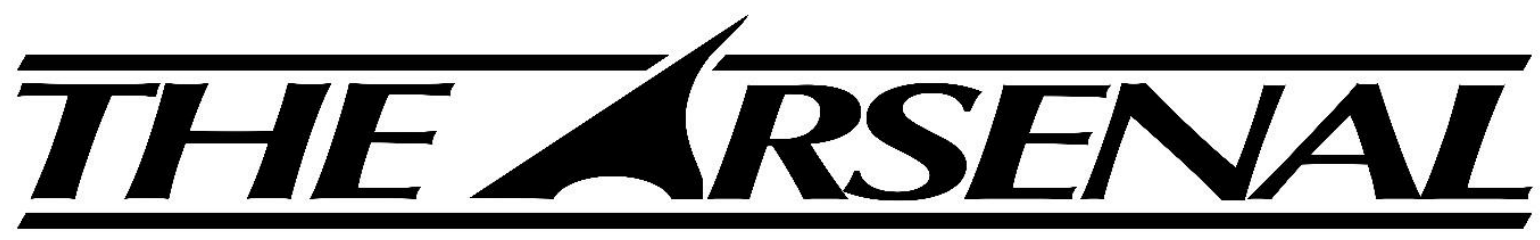

\section{Augusta University's Undergraduate Research Journal}

ISSN 2380-5064 | The Arsenal is published by the Augusta University Libraries | http://guides.augusta.edu/arsenal

Volume 3, Issue 2 (2020)

Special Edition Issue

\section{DIAGNOSIS OF MENTAL ILLNESS IN THE NARRATOR OF CHARLOTTE GILMAN'S “THE YELLOW WALLPAPER” USING THE DSM-5}

\section{Wayne Fang and Tim Sadenwasser}

\section{Citation}

Fang, W., \& Sadenwasser, T. (2020). Diagnosis of mental illness in the narrator of Charlotte Gilman's “The Yellow Wallpaper" using the DSM-5. The Arsenal: The Undergraduate Research Journal of Augusta University, 3(2), http://doi.org/10.21633/issn.2380.5064/s.2020.03.02.08 


\section{Diagnosis of Mental Illness in the Narrator of Charlotte Perkin Gilman's “The Yellow Wallpaper" Using the DSM-5}

Presenter: Wayne Fang (Poster Presentation)

Authors: Wayne Fang ${ }^{1}$ and Tim Sadenwasser ${ }^{2}$

Faculty Sponsor(s): Tim Sadenwasser, $\mathrm{PhD}$

Department Affiliation: ${ }^{1}$ Biological Sciences, ${ }^{2}$ English and Foreign Languages

\section{ABSTRACT}

Charlotte Perkin Gilman's “The Yellow Wallpaper" explores mental illness, freedom, and the faults of the rest cure by exploring the life of a wife who has been diagnosed with neurasthenia. In this story, Gilman describes an increasingly common practice during her time and how problematic it was for individuals who were diagnosed with neurasthenia. Through the wife's narration, Gilman shows how many women felt trapped since they were forced to undertake the rest cure due to one-sided relationship dynamics. Using this narrative of the wife's deteriorating mental health, Gilman argues for equality in relationships as well as better treatments for mental health. In this presentation, I will use the Diagnostic and Statistics Manual of Mental Disorders (DSM-5) as well as other scholarly sources to diagnose the wife's mental illness. To do this, I will take the wife's narration and compare it to diagnostic criteria as presented in the DSM-5. By examining the narrator's thoughts and actions, I will be able to examine the progression of her mental illness. Examining the wife's mental health can show how many women of her time period may have felt trapped. This in turn can explain how many women faced unequal power dynamics in their marriages. 


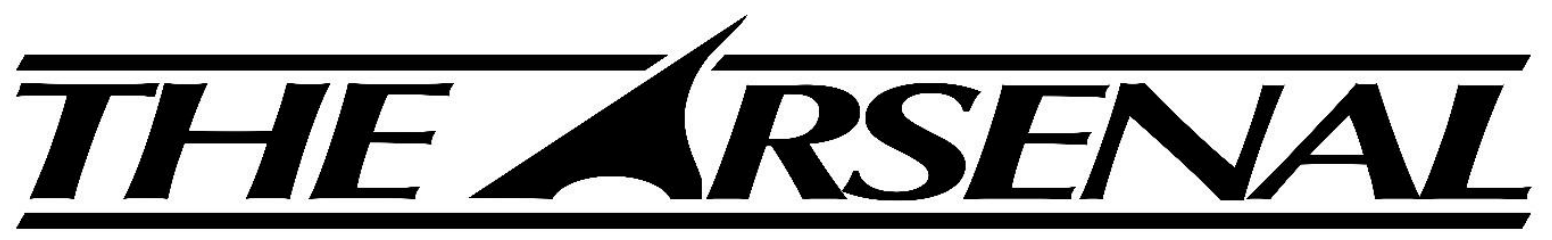

\section{Augusta University's Undergraduate Research Journal}

ISSN 2380-5064 | The Arsenal is published by the Augusta University Libraries | http://guides.augusta.edu/arsenal

Volume 3, Issue 2 (2020)

Special Edition Issue

\section{USING MACHINE LEARNING TO PREDICT THE CRITICAL REYNOLDS NUMBER OF A TANDEM CYCLINDER SYSTEM}

Ivan A. Florentino, Josefa Guerrero-Millan, and Trinanjan Datta

\section{Citation}

Florentino, I., Guerrero-Millan, J., \& Datta, T. (2020). Using machine learning to predict the critical reynolds number of a tandem cylinder system. The Arsenal:

The Undergraduate Research Journal of Augusta University, 3(2), http://doi.org/10.21633/issn.2380.5064/s.2020.03.02.09 


\title{
Using Machine Learning to Predict the Critical Reynolds Number of a Tandem Cylinder System
}

Presenter: Ivan A. Florentino (Oral Presentation)

Authors: Ivan A. Florentino, Josefa Guerrero-Millan, and Trinanjan Datta

Faculty Sponsor(s): Josefa Guerrero-Millan, $\mathrm{PhD}$ and Trinanjan Datta, $\mathrm{PhD}$

Department Affiliation: Chemistry and Physics

Funding: Augusta University CURS Summer Scholars Program

\begin{abstract}
Fluid flow past two cylinders placed next to each other (tandem configuration) is common in engineering applications. We utilize machine learning techniques coupled with computational fluid dynamics simulation to predict the critical Reynolds number of a tandem configuration. First, we compute the flow behavior using Gerris. We find that for certain special choices of cylinder separation to diameter ratio the flow evolves from laminar to oscillatory (turbulent) behavior at a specific critical Reynolds number. While it is possible to extract the pressure data to analyze the transition, a computational bottleneck is the sheer volume of the generated information. In our work, we have utilized singular value decomposition (SVD) and principal component analysis (PCA) to identify the critical Reynolds number. These techniques allowed us to remove irrelevant simulation information by reducing the data matrix dimension. Based on our calculations, we show that it is possible to reconstruct the pressure around the cylinder using a minimal amount of data to predict the correct critical number.
\end{abstract}




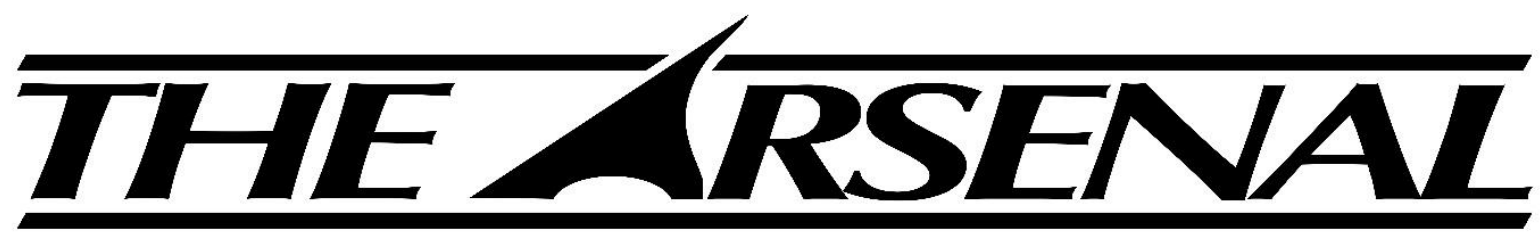

\title{
Augusta University's Undergraduate Research Journal
}

ISSN 2380-5064 | The Arsenal is published by the Augusta University Libraries | http://guides.augusta.edu/arsenal

Volume 3, Issue 2 (2020)

Special Edition Issue

\section{CBD ANALYSIS IN OILS AND FOODS}

\author{
Joanna Foley and Stephanie Myers
}

\section{Citation}

Foley, J., \& Myers, S. (2020). CBD analysis in oils and foods. The Arsenal:

The Undergraduate Research Journal of Augusta University, 3(2), http://doi.org/10.21633/issn.2380.5064/s.2020.03.02.10 


\title{
CBD Analysis in Oils and Foods
}

Presenter: Joanna Foley (Oral Presentation)

Authors: Joanna Foley and Stephanie Myers

Faculty Sponsor(s): Stephanie Myers, $\mathrm{PhD}$

Department Affiliation: Chemistry and Physics

Funding: Augusta University Department of Chemistry and Physics

\begin{abstract}
Cannabidiol (CBD) has become a very prominent topic in the medical community and popular marketplace because of its widespread consumer use. Tetrahydrocannabinol (THC) and other similar molecules can be present in commercial CBD products, so testing is necessary to determine the presence of the CBD. Existing methods of analysis for CBD oils are only known on GC-FID (gas chromatography - flame ionization detector) and these methods are not optimal for the wide variety of commercial CBD products available. Thus, a GC-MS (mass spectroscopy) method, based on a published GC-FID method, was created to optimize the detection of CBD because not only can separation be obtained but also identification, as well. This analysis method can be applied to a wide variety of foods, gummies, and other items that may contain CBD or similar molecules. The method has been optimized by varying GC column temperature and sample preparation to find a balance between analysis time, analyte detection, and resolution for the various types of cannabinoid molecules present in commercial CBD oil samples. The optimized method was able to determine that a 1:3 ratio of oil to solvent gave optimal signal of all CBD oils tested. The optimized method was then tested on a variety of commercial and self-prepared CBD edibles to determine that CBD was still present and was not degraded into THC.
\end{abstract}

Received: 01/31/2020 Accepted: 02/17/2020

Correspondence: Joanna Foley, Augusta University, 1120 15 $5^{\text {th }}$ St. Augusta, GA 30912, jofoley@augusta.edu 


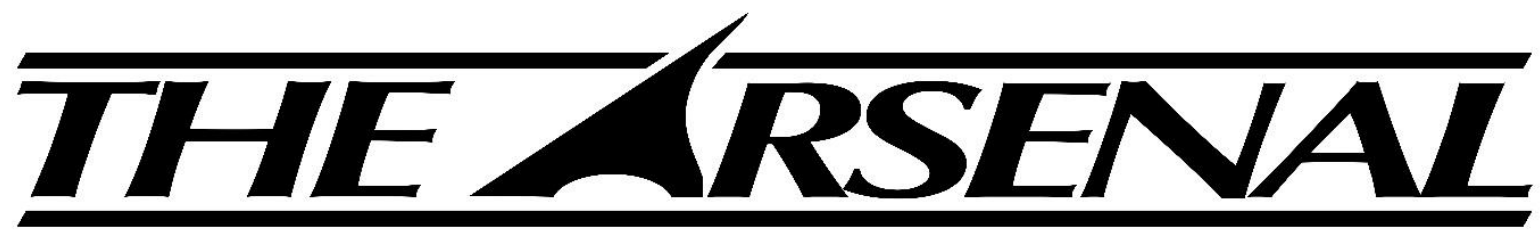

Augusta University's Undergraduate Research Journal

ISSN 2380-5064 | The Arsenal is published by the Augusta University Libraries | http://guides.augusta.edu/arsenal

Volume 3, Issue 2 (2020)

Special Edition Issue

PERFLUOROOCTANOIC ACID (IN THE PRESENCE

OF FETAL BOVINE SERUM) INDUCES

PROLIFERATION IN ER $\alpha$ POSTIVE AND ER $\alpha$

NEGATIVE BREAST CANCER CELL LINES

Victoria Gaw, Manderrious Glenn, and Jennifer Cannon

\section{Citation}

Graw, V., Glenn, M., \& Cannon, J. (2020). Perfluorooctanoic acid (in the presence of fetal bovine seruym) induces proliferation in ER $\alpha$ Positive and ER $\alpha$ Negative breast cancer cell lines. The Arsenal: The Undergraduate Research Journal of Augusta University, 3(2), http://doi.org/10.21633/issn.2380.5064/s.2020.03.02.11

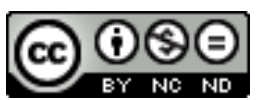

(C) Graw, Glenn, and Cannon 2020. This open access article is distributed under a Creative Commons Attribution NonCommercial-NoDerivs 2.0 Generic License (https://creativecommons.org/licenses/by-nc-nd/2.0/). 


\section{Perfluorooctanoic Acid (in the Presence of Fetal Bovine Seruym) Induces Proliferation in ER $\alpha$ Positive and ER $\alpha$ Negative Breast Cancer Cell Lines}

Presenter: Victoria Gaw (Poster Presentation)

Authors: Victoria Gaw, Manderrious Glenn, and Jennifer Cannon

Faculty Sponsor(s): Jennifer Cannon, $\mathrm{PhD}$

Department Affiliation: Biological Sciences

Funding: Augusta University CURS Student Research Grant, Department of Biological Sciences

\section{ABSTRACT}

Perfluorooctanoic acid (PFOA) is a synthetic chemical belonging to a larger group of fluorotelomers. These compounds have been used in the production of both industrial and consumer products as surfactants and are environmentally persistent pollutants. While the long-term effects of PFOA are largely unknown, there is increasing evidence suggesting it to be an endocrine disruptor. Studies have shown that PFOA binds to and activates peroxisome-proliferator-activated receptor $\alpha(\operatorname{PPAR} \alpha)$, which can regulate the expression of other genes and receptors. Previous experiments in our lab demonstrated that PFOA treatment of MCF-7 breast cancer cells (an ER $\alpha$-positive cell line) decreased expression of ER $\alpha$ mRNA and protein, and decreased cell viability by $\sim 20 \%$ within $48 \mathrm{~h}$ of treatment compared to DMSO controls. However, these cells were treated in the absence of fetal bovine serum (FBS). When we repeated these experiments without serum withdrawal, we initially noted a tendency towards increased proliferation in MCF-7 cells treated with $50 \mu \mathrm{M}$ and $100 \mu \mathrm{M}$ PFOA at both $24 \mathrm{~h}$ and $48 \mathrm{~h}$ compared to control. To further examine the role of ER $\alpha$ in this PFOA-induced proliferation, we carried out additional experiments in MCF-7 cells along with experiments in another ER $\alpha$-positive cell line, T47D, as well as an ER $\alpha$-negative cell line, MDA-MB-23.

Received: 01/31/2020 Accepted: 02/17/2020

Correspondence: Victoria Gaw, Augusta University, $112015^{\text {th }}$ St. Augusta, GA 30912, vgaw@augusta.edu 


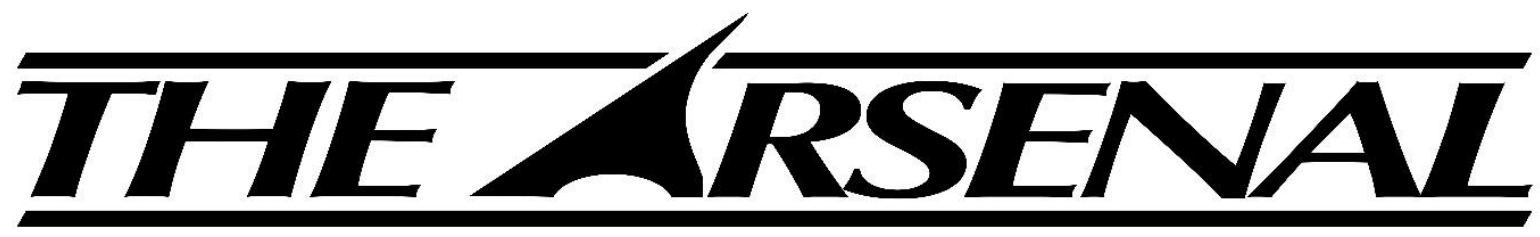

Augusta University's Undergraduate Research Journal

ISSN 2380-5064 | The Arsenal is published by the Augusta University Libraries | http://guides.augusta.edu/arsenal

Volume 3, Issue 2 (2020)

Special Edition Issue

FAST-TRACK EXTUBATION IN INFANCY AND EARLY CHILDHOOD FOLLOWING HEART SURGERY: OUTCOME ANALYSIS AND PREDICTORS OF FAILURE

Emma Geister, Raquel Esquivel, Danielle Crethers, Danalynn Weatherholt, Maria Gabriela Sanchez, Gustavo Munoz, and Anastasios C. Polimenakos

\section{Citation}

Geister, E., Esquivel, R., Crethers, D., Weatherholt, D., Sanchez, M. G., Munoz, G. $\&$ Polimenakos, A. C. (2020). Fast-track extubation in infancy and early childhood following heart surgery: Outcome analysis and predictors of failure. The Arsenal: The Undergraduate Research Journal of Augusta University, 3(2), http://doi.org/10.21633/issn.2380.5064/s.2020.03.02.12

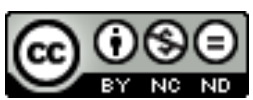

(C) Geister et al. 2020. This open access article is distributed under a Creative Commons Attribution NonCommercial-NoDerivs 2.0 Generic License (https://creativecommons.org/licenses/by-nc-nd/2.0/). 


\section{Fast-Track Extubation in Infancy and Early Childhood Following Heart Surgery: Outcome Analysis and Predictors of Failure}

Presenter: Emma Geister (Poster Presentation)

Authors: Emma Geister ${ }^{1}$, Raquel Esquivel ${ }^{1}$, Danielle Crethers ${ }^{2}$, Danalynn Weatherholt ${ }^{2}$, Maria Gabriela Sanchez ${ }^{2}$, Gustavo Munoz ${ }^{2}$, Anastasios C. Polimenakos²

Faculty Sponsor(s): Anastasios C. Polimenakos, MD

Department Affiliation: ${ }^{1}$ Biological Sciences, ${ }^{2}$ Medical College of Georgia

Funding: Augusta University CURS Summer Scholars Program

\section{ABSTRACT}

Early extubation (EE) has become a critical determinant in perioperative management following congenital heart surgery (CHS) during early childhood. Fast track (FT) strategies and EE, when feasible, can have beneficial effects on clinical outcomes. The authors sought to determine the impact of EE on clinical outcomes, total hospital costs, identify predictors of failure and suggested criteria for new patients. A retrospective chart review of children $\leq 6$ years old $(n=64)$ who underwent CHS between January-December 2017 was performed. EE was defined as successful removal of the endotracheal tube in the operating room or upon arrival in intensive care unit (ICU). Groups were identified as (A):EE/Fast track and (B):no EE. Determinants for EE failure were assessed, and cost analysis pursued. The authors found 39 patients with EE compared to 25 that were not. Children who were $E E$ (mean $=6.795$ days, $s d=4.250)$ spend significantly less $(\mathrm{p}<0.0001)$ overall time in the ICU compared to non-EE patients (mean=19.960 days, $s d=13.081$ ). The authors also found that the total hospital stay for patients who were EE (mean=6.976 days, $\mathrm{sd}=4.090$ ) was significantly reduced compared to those who were not (mean $=21.783$ days, $\mathrm{sd}=13.450)(\mathrm{p}<0.0001)$. Furthermore, the authors found that children who were EE had a significant reduction ( $\mathrm{p}<0.0001, \mathrm{sd}=23,196.203$ ) in total hospital cost than patients who were not EE. Based on our analysis, we concluded that EE is feasible following CHS during early childhood but requires team approach and thoughtful use of FT protocols.

Correspondence: Emma Geister, Augusta University, 1120 15 ${ }^{\text {th }}$ St. Augusta, GA 30912, egeister@augusta.edu 


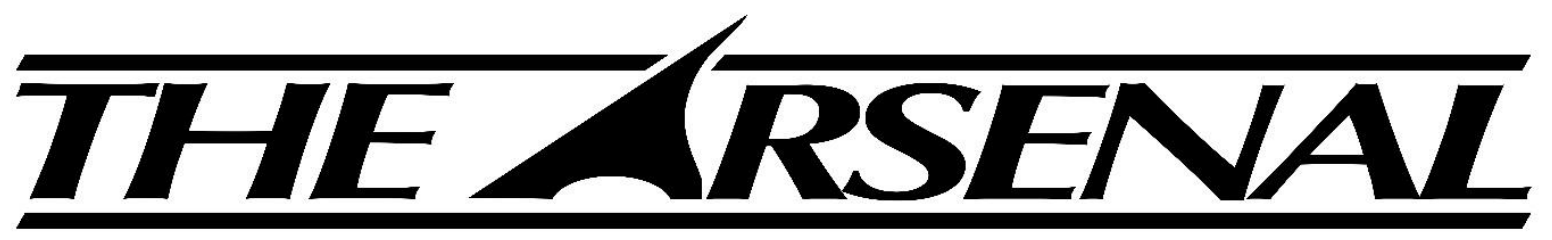

\section{Augusta University's Undergraduate Research Journal}

ISSN 2380-5064 | The Arsenal is published by the Augusta University Libraries | http://guides.augusta.edu/arsenal

Volume 3, Issue 2 (2020)

Special Edition Issue

\section{SCHIZOAFFECTIVE DISORDER DEPRESSIVE TYPE IN “THE YELLOW WALLPAPER” BY CHARLOTTE PERKINS GILMAN}

\section{Lindsey German and Tim Sadenwasser}

\section{Citation}

German, L., \& Sadenwasser, T. (2020). Schizoaffective disorder depressive type in "The Yellow Wallpaper" by Charlotte Perkins Gilman. The Arsenal:

The Undergraduate Research Journal of Augusta University, 3(2), http://doi.org/10.21633/issn.2380.5064/s.2020.03.02.13 


\title{
Schizoaffective Disorder Depressive Type in "The Yellow Wallpaper" by Charlotte Perkins Gilman
}

Presenter: Lindsey German (Poster Presentation)

Authors: Lindsey German and Tim Sadenwasser

Faculty Sponsor(s): Tim Sadenwasser, $\mathrm{PhD}$

Department Affiliation: English and Foreign Languages

\begin{abstract}
Charlotte Perkins Gilman's short story "The Yellow Wallpaper" is a literary work of empowering women and serves to explore the human psyche upon women in the 19th century. The author wanted to create a story that brought people's attention to the rest cure treatment, and how it was not beneficial for the mind. It actually has detrimental effects on one's mind, because the rest cure isolates that person in a room with nothing to do but to essentially "go crazy." Therefore, the author wanted to warn people about this form of treatment through the downward spiral of the narrator's mental health in the story. In my presentation, I will use other literary references and descriptions given from the short story to show the audience evidence of the narrator's behavior with the character diagnosis of schizoaffective disorder depressive type. To do this, I plan on discussing the criteria of the diagnosis from the DSM-V and how these criteria are met in the short story. This criterion includes a major depressive episode and schizophrenic symptoms. The narrator of Gilman's story displays her depressive mood within the story by crying all day at nothing; she displays her schizophrenic symptoms when she experiences delusions, hallucinations, and social withdrawal. I also plan on discussing how the sociocultural factors involving the rest cure treatment given to the narrator and her relationship with her husband further diminishes her mental health. This mental instability that she experiences causes much distress in her life to the point where she could not take it anymore.
\end{abstract}

Received: 01/31/2020 Accepted: 02/17/2020

Correspondence: Lindsey German, Augusta University, $112015^{\text {th }}$ St. Augusta, GA 30912, 1german@augusta.edu 


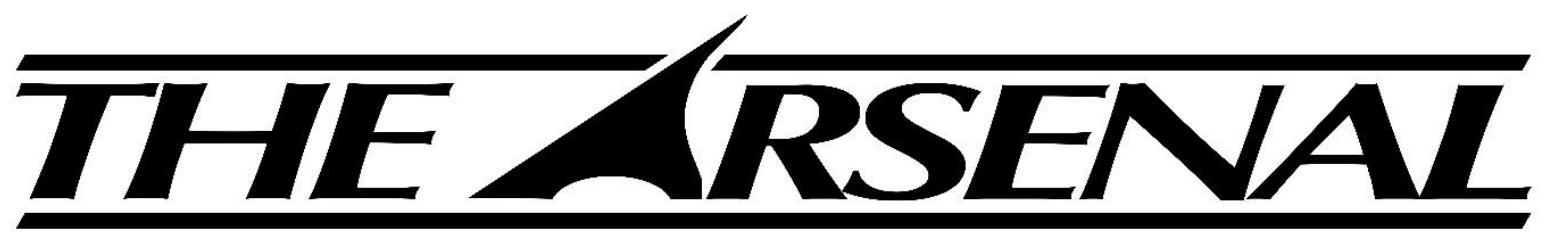

\section{Augusta University's Undergraduate Research Journal}

ISSN 2380-5064 | The Arsenal is published by the Augusta University Libraries | http://guides.augusta.edu/arsenal

Volume 3, Issue 2 (2020)

Special Edition Issue

\section{DEVELOPMENT OF AN ALTERNATIVE ENERGY SYNTHETIC PATHWAY TO NYLON 6,6 THROUGH THE USE OF SOLAR IRRADIATION AS THE SOLE HEAT SOURCE}

\section{Caroline Hammond and Brian M. Agee}

\section{Citation}

Hammond, C., \& Agee, B. (2020). Development of an alternative energy synthetic pathway to nylon 6,6 through the use of solar irradiation as the sole heat source.

The Arsenal: The Undergraduate Research Journal of Augusta University, 3(2), http://doi.org/10.21633/issn.2380.5064/s.2020.03.02.14 


\section{Development of an Alternative Energy Envelopment of an Alternative Energy Synthetic Pathway to Nylon 6,6 Through the Use of Solar Irradiation as the Sole Heat Source}

Presenter: Caroline Hammond (Poster Presentation)

Authors: Caroline Hammond and Brian M. Agee

Faculty Sponsor(s): Brian M. Agee, $\mathrm{PhD}$

Department Affiliation: Chemistry and Physics

\section{ABSTRACT}

Recently, scientists have attempted to transform traditional synthetic procedures into ones that are more environmentally favorable due to the desire to circumvent the damage being done to our environment. A technique was recently developed in which satellite dishes were repurposed as solar reflectors that are capable of providing a focused source of solar irradiation. The ability to use the solar reflector as the sole heat source for synthetic reactions has been analyzed for the synthesis of the commercially important polyamide, nylon 6,6. Commercially, nylon 6,6 is synthesized using a multi-step procedure, in which nearly all of the steps require the addition of heat in order for the reaction to occur. Furthermore, the synthesis also incorporates some chemicals and reagents that are not environmentally friendly or consist of elements that are considered endangered and their supply is severely limited. The exchange of these reagents with more environmentally friendly, sustainable substitutes has been analyzed for the total synthesis of nylon 6,6. The incorporation of a solar energy heat source and use of environmentally friendly chemicals provides a new synthetic route to nylon 6,6 that can be taught in teaching labs as a "green synthesis" experiment or scaled to fit the needs of industrial synthesis. 


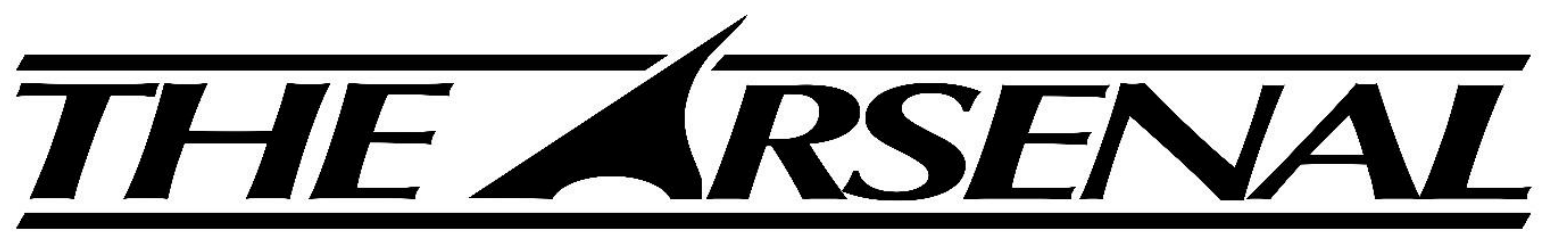

\section{Augusta University's Undergraduate Research Journal}

ISSN 2380-5064 | The Arsenal is published by the Augusta University Libraries | http://guides.augusta.edu/arsenal

Volume 3, Issue 2 (2020)

Special Edition Issue

\section{PREHISTORIC DINOSAURS: AN EXPLORATION OF FACT VS. FICTION THROUGH THE CREATION OF COMPARATIVE SCULPTURAL FORMS}

\section{Krista Havens, Jennifer Onofrio, and Thomas Crowther}

\section{Citation}

Havens, K., Onofrio, J., \& Crowther, T. (2020). Prehistoric dinosaurs: An exploration of fact vs fiction through the creation of comparative sculptural forms. The Arsenal: The Undergraduate Research Journal of Augusta University, 3(2), http://doi.org/10.21633/issn.2380.5064/s.2020.03.02.15 


\title{
Prehistoric Dinosaurs: An Exploration of Fact vs. Fiction Through the Creation of Comparative Sculptural Forms
}

Presenter: Krista Havens (Poster Presentation)

Authors: Krista Havens, Jennifer Onofrio, and Thomas Crowther

Faculty Sponsor(s): Jennifer Onofrio, M.F.A and Thomas Crowther, M.F.A

Department Affiliation: Art and Design

\begin{abstract}
Prehistoric Dinosaurs: An Exploration of Fact vs. Fiction Through the Creation of Comparative Sculptural Forms is an art exhibition which displays the differences between how dinosaurs look in film and media versus how they are proposed to have looked based on scientific findings. The impetus for this project was to create a kid-friendly educational tool, comprised of three hand-sculpted dinosaurs and three resin cast dinosaurs. The species of dinosaurs created were Carnotaurus, Velociraptor, and Dilophosaurus, which are some of the most commonly portrayed dinosaurs in the film industry. Each scientifically accurate dinosaur sculpture will be placed next to its film and media representation counterpart to allow for the viewer to compare and contrast the differences in the physical appearances.
\end{abstract}




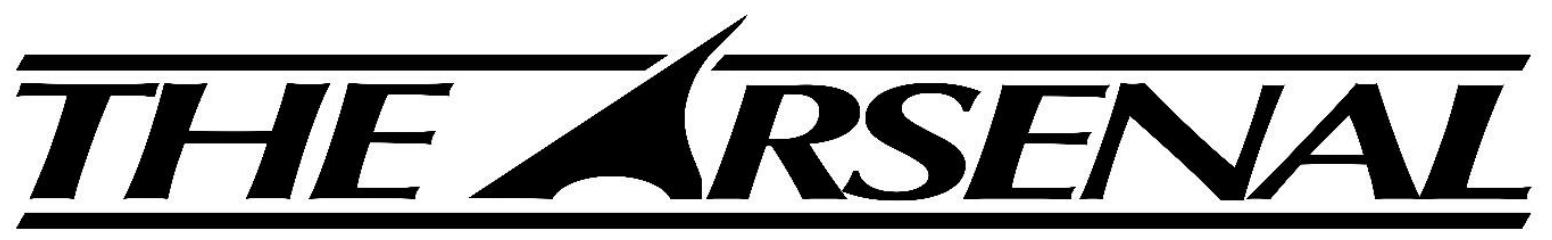

\section{Augusta University's Undergraduate Research Journal}

ISSN 2380-5064 | The Arsenal is published by the Augusta University Libraries | http://guides.augusta.edu/arsenal

Volume 3, Issue 2 (2020)

Special Edition Issue

\section{THE DETECTION AND PREVALENCE OF MICROSPORIDIA IN SHRIMP FROM THE SATILLA RIVER ESTUARY}

\section{Miranda Henderson, Jenelly Canela, Jeffrey Fischer, and Jessica Reichmuth}

\section{Citation}

Henderson, M., Canela, J., Fischer, J., \& Reichmuth, J. (2020). The detection and prevalence of microsporidia in shrimp from the Satilla River Estuary. The Arsenal:

The Undergraduate Research Journal of Augusta University, 3(2), http://doi.org/10.21633/issn.2380.5064/s.2020.03.02.16 


\title{
The Detection and Prevalence of Microsporidia in Shrimp from the Satilla River Estuary
}

Presenter: Miranda Henderson (Poster Presentation)

Authors: Miranda Henderson, Jenelly Canela, Jeffrey Fischer, and Jessica Reichmuth

Faculty Sponsor(s): Jeffrey Fischer, $\mathrm{PhD}$ and Jessica Reichmuth, $\mathrm{PhD}$

Department Affiliation: Biological Sciences

\begin{abstract}
Microsporidia are spore-forming obligate intracellular parasitic fungi that infect eukaryotic organisms. They are ubiquitous in nature and infections occur worldwide in terrestrial and aquatic hosts. Some species of Microsporidia have been shown to infect the hepatopancreas of shrimp, which may affect their ability to obtain nutrients, stunt their growth, and increase their susceptibility to additional diseases. Microsporidiosis in shrimp has been shown to negatively impact the commercial shrimp industry, resulting in great economic loss, specifically to the state of Georgia since this fishery is the largest and most lucrative. This study was conducted to evaluate the prevalence of Microsporidia in shrimp from the Satilla River Estuary in Georgia because of the man-made cuts that have altered water quality conditions, which could affect shrimp health specifically. Shrimp were caught at four collection sites using $6.1 \mathrm{~m}$ (20ft) otter trawls and cast nets and were transported on ice back to the lab where they were frozen until dissection. Using brightfield light microscopy and a previously established staining technique, microsporidian spores were detected in hepatopancreas' extracts in greater than 30 percent of the shrimp analyzed.
\end{abstract}

Received: 01/31/2020 Accepted: 02/17/2020

Correspondence: Miranda Henderson, Augusta University, $112015^{\text {th }}$ St. Augusta, GA 30912, mirhenderson@augusta.edu 


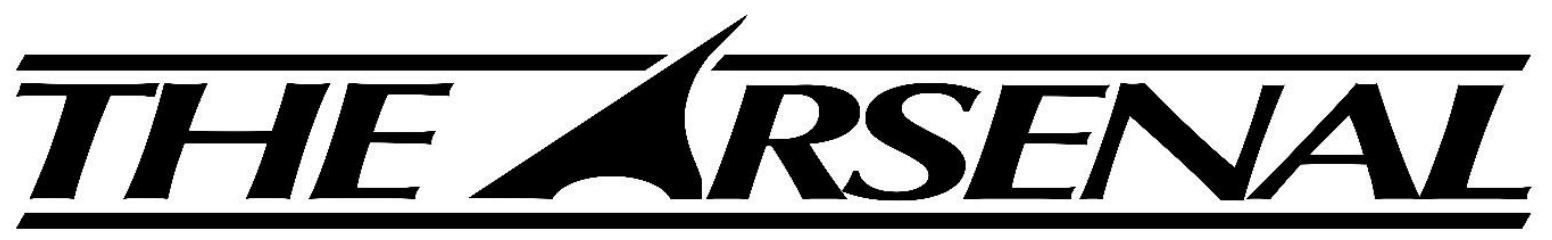

\section{Augusta University's Undergraduate Research Journal}

ISSN 2380-5064 | The Arsenal is published by the Augusta University Libraries | http://guides.augusta.edu/arsenal

Volume 3, Issue 2 (2020)

Special Edition Issue

EVALUATION OF MAMMAL HAIR AS A

POTENTIAL WILD PIG REPELLENT ON COWDEN

PLANTATION IN JACKSON, SOUTH CAROLINA

Samantha R. Hitchens and Bruce Saul

\section{Citation}

Hitchens, S., \& Saul, B. (2020). Evaluation of mammal hair as a potential wild pig repellent on in Cowden Plantation, Jackson, South Carolina.

The Arsenal: The Undergraduate Research Journal of Augusta University, 3(2), http://doi.org/10.21633/issn.2380.5064/s.2020.03.02.17 


\title{
Evaluation of Mammal Hair as a Potential Wild Pig Repellent on Cowden Plantation in Jackson, South Carolina
}

Presenter: Samantha R. Hitchens (Poster Presentation)

Authors: Samantha R. Hitchens and Bruce Saul

Faculty Sponsor(s): Bruce Saul, $\mathrm{PhD}$

Department Affiliation: Biological Sciences

Funding: Augusta University CURS Student Research Grant

\begin{abstract}
Invasive wild pigs (Sus scrofa) have a destructive impact across the world. The variety of cultures affected make the development of more effective and diverse management methods vital. Although wild pigs are often hunted with dogs, this method is not suitable or legal in all areas. Considering this, and pigs' highly developed sense of smell, the following hypothesis was developed: Can a natural scent function as a satisfactory pig repellant? To test our hypothesis, we attracted wild pigs into areas baited with corn and performed separate trials by adding hair from four different mammal species (dog, cat, horse, and coyote). Our experimental design forced pigs to interact with the hair before consuming the bait. Trail cameras monitored each location over a five-month period and wild pig behaviors were recorded. The presence and absence of pigs throughout the study trials was analyzed and compared with images captured during the control trials (with corn only). Image totals were evaluated to determine if the hair prevented pigs from entering any areas. The duration of any absences was noted. The results support our hypothesis that a natural scent (dog hair) can decrease wild pig activity and potentially serve as a repellant.
\end{abstract}

Received: 01/31/2020 Accepted: 02/17/2020

Correspondence: Samantha Hitchens, Augusta University, $112015^{\text {th }}$ St. Augusta, GA 30912, shitche1@augusta.edu 


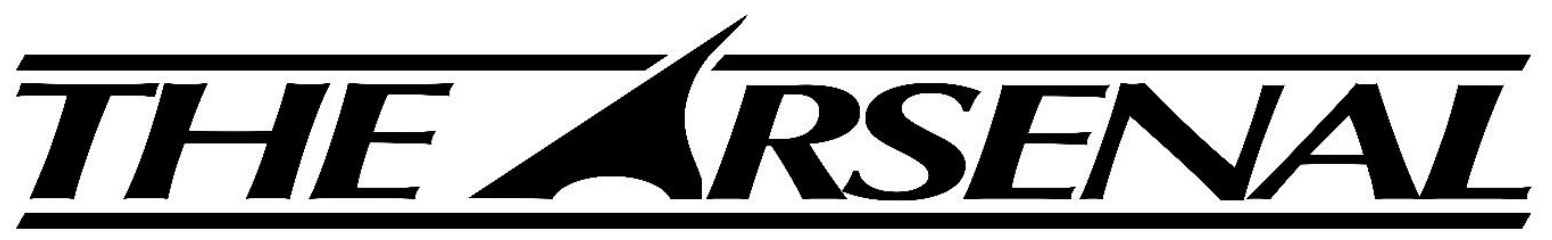

\section{Augusta University's Undergraduate Research Journal}

ISSN 2380-5064 | The Arsenal is published by the Augusta University Libraries | http://guides.augusta.edu/arsenal

Volume 3, Issue 2 (2020)

Special Edition Issue

\section{MINDFULNESS MEDITATION THROUGH A MOBILE APP}

Sabrina Huff, Cleston-Lee Murray, Leigha Restrepo, Shelby Jones, and Sabina Widner

\section{Citation}

Huff, S., \& Murray, C., Restrepo, L., Jones, S., \& Widner, S. (2020).

Mindfulness meditation through a mobile app. The Arsenal: The

Undergraduate Research Journal of Augusta University, 3(2), http://doi.org/10.21633/issn.2380.5064/s.2020.03.02.18 


\section{Mindfulness Meditation through a Mobile App}

Presenter: Sabrina Huff (Poster Presentation)

Authors: Sabrina Huff, Cleston-Lee Murray, Leigha Restrepo, Shelby Jones, and Sabina Widner

Faculty Sponsor(s): Sabina Widner, $\mathrm{PhD}$

Department Affiliation: Psychological Sciences

\section{ABSTRACT}

Personal health is an important aspect of the self. In order to change health, behavior must also be changed. Changing behavior is often effortful and many do not adhere to desired changes. The Theory of Planned Behavior (TPB; Ajzen, 1991) suggests that self-efficacy, attitudes, intention, and subjective norms all play a part in behavior change. The present study examined each of these components as it relates to a particular behavior change, that is, mindfulness meditation. We hypothesized that self-efficacy, attitudes, intention, and subjective norms would positively correlate with the number of minutes spent meditating. Participants were 144 undergraduates who volunteered for this two-part study. Time One included educating individuals on mindfulness meditation, followed with instructions to meditate for the next six days, log meditation minutes using a mobile app (Smiling Mind), and complete a survey adapted by Azjen (2002) measuring self-efficacy, attitudes, intentions, and subjective norms related to meditating. Time Two consisted of collection of meditation data and another survey on the experience of meditating. Preliminary analyses suggested no relationship between any of the TPB components and meditation, which may cast doubt on the reliability of the TPB constructs to predict behavior change.

Ajzen, I. (1991). The theory of planned behavior. Organizational Behavior and Human Decision Processes, 50(2), 179-211. https://doi.org/10.1016/0749-5978(91)90020-T

Azjen, I. (2002). Constructing a TpB questionnaire: Conceptual and methodological considerations. Available at: http://people.umass.edu/aizen/pdf/tpb.measurement.pdf.

Received: 01/31/2020 Accepted: 02/17/2020

Correspondence: Sabrina Huff, Augusta University, $112015^{\text {th }}$ St. Augusta, GA 30912, sahuff@augusta.edu 


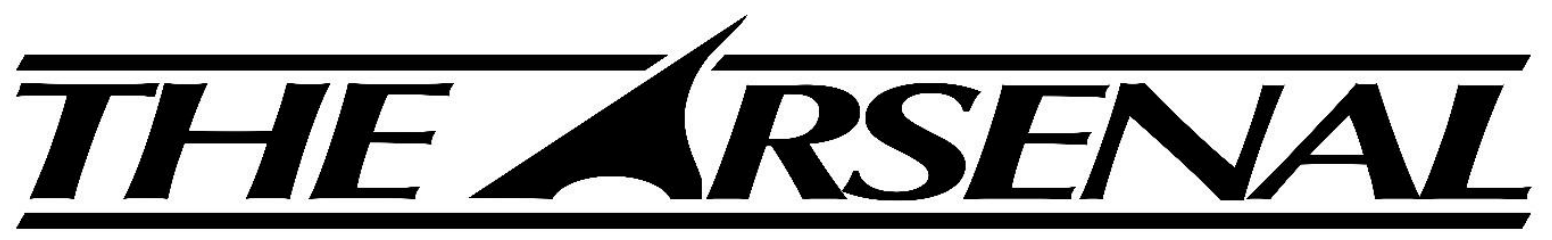

\section{Augusta University's Undergraduate Research Journal}

ISSN 2380-5064 | The Arsenal is published by the Augusta University Libraries | http://guides.augusta.edu/arsenal

Volume 3, Issue 2 (2020)

Special Edition Issue

IMPLEMENTING THE HEALTHY UNIVERSITY

APPROACH TO MENTAL HEALTH AT

AUGUSTA UNIVERSITY

Lauren Jackson, Candace Best, Josefa Guerrero-Milan, and Vahé Heboyan

\section{Citation}

Jackson, L., Best, C., Guerrero-Milan, J., \& Heboyan, V. (2020). Implementing the healthy university approach to mental health at Augusta University.

The Arsenal: The Undergraduate Research Journal of Augusta University, 3(2), http://doi.org/10.21633/issn.2380.5064/s.2020.03.02.19

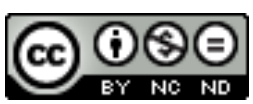

(C) Jackson et al. 2020. This open access article is distributed under a Creative Commons Attribution NonCommercial-NoDerivs 2.0 Generic License (https://creativecommons.org/licenses/by-nc-nd/2.0/). 


\title{
Implementing the Healthy University Approach to Mental Health at Augusta University
}

Presenter: Lauren Jackson (Oral Presentation)

Authors: Lauren Jackson ${ }^{1}$, Candace Best ${ }^{1}$, Josefa Guerrero-Milan² ${ }^{2}$, and Vahé Heboyan ${ }^{3}$

Faculty Sponsor(s): Candace Best, PhD, Josefa Guerrero-Milan, PhD, and Vahé Heboyan, PhD

Department Affiliation: ${ }^{1}$ Psychological Sciences, ${ }^{2}$ Chemistry and Physics, ${ }^{3}$ Population Health Sciences

\begin{abstract}
In university systems, there is a lack of knowledge and understanding of student perceptions and utilizations of campus mental health services. This lack of knowledge can be expanded by evaluating the state of campus mental health services, interviewing clinical staff, and by evaluating the needs of students. The objective of this study is to use Healthy University programming to devise health initiatives to benefit the mental health of students at Augusta University. Student needs will be evaluated by surveying their perceptions and utilizations of campus mental health services. Survey data will be collected anonymously through Qualtrics. Clinical staff at Student Counseling and Psychological Services (SCAPS) will be interviewed privately. The evaluation of SCAPS will be completed by reviewing student utilization data which will be collected by SCAPS in yearly reports. Self-reported student mental health and perceptions of SCAPS will be analyzed by using statistical tests and multivariate regression analyses. With the data collected, health initiatives will be theorized to strengthen SCAPS so that the mental health services provided will continue to benefit Augusta University students and serve their needs effectively.
\end{abstract}

Received: 01/31/2020 Accepted: 02/17/2020

Correspondence: Lauren Jackson, Augusta University, 1120 15 th St. Augusta, GA 30912, laujackson@augusta.edu 


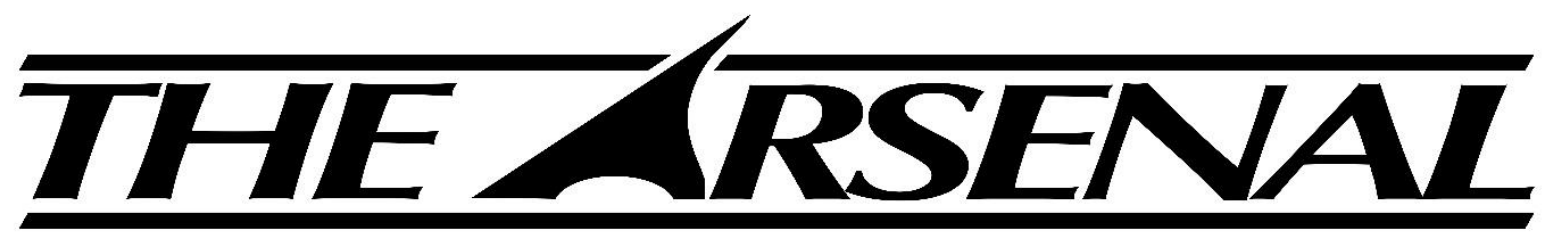

\section{Augusta University's Undergraduate Research Journal}

ISSN 2380-5064 | The Arsenal is published by the Augusta University Libraries | http://guides.augusta.edu/arsenal

Volume 3, Issue 2 (2020)

Special Edition Issue

\section{ATAD3A: A CRITICAL DRIVER FOR HEAD AND NECK CANCER}

Caleb Jensen, Liwei Lang, and Yong Teng

\section{Citation}

Jensen, C., Lang, L., \& Teng, Y. (2020). ATAD3A: A critical driver for head and neck cancer. The Arsenal: The Undergraduate Research Journal of Augusta University, 3(2), http://doi.org/10.21633/issn.2380.5064/s.2020.03.02.20 


\section{ATAD3A: A Critical Driver for Head and Neck Cancer}

Presenter: Caleb Jensen (Poster Presentation)

Authors: Caleb Jensen ${ }^{1}$, Liwei Lang ${ }^{2}$, and Yong Teng ${ }^{3}$

Faculty Sponsor(s): Yong Teng, $\mathrm{PhD}$

Department Affiliation: ${ }^{1}$ Biological Sciences, ${ }^{2}$ Oral Biology, ${ }^{3}$ Georgia Cancer Center

Funding: Augusta University CURS Summer Scholars Program

\section{ABSTRACT}

For patients with head and neck cancer whose tumors are HPV negative HPV(-), current therapy does not lead to significant longevity and most succumb to loco-regional recurrence of the primary tumor. We discovered that HPV(-) head and neck squamous cell carcinoma (HNSCC) highly expressed ATPase family AAA-domain containing protein 3A (ATAD3A). ATAD3A is the mitochondrial protein which has been demonstrated as an oncogene in breast and lung cancer; however, nothing has been reported regarding its role in HNSCC. Using the HPV(-) HNSCC cell line HN12 as a cell model, we show here that knockout of ATAD3A expression by CRISPR-CAS9 in HNSCC cells leads to reduced cell proliferation and decreased the ability of colony formation and anchorageindependent growth in soft agar. Importantly, ATAD3A loss also significantly suppressed HNSCC cells to grow in $3 \mathrm{D}$ culture. Together, these findings suggest the potential oncogenic role of ATAD3A in HNSCC cells, and implicate that ATAD3A represents a promising target for better treatment of patients with HPV(-) HNSCC.

Received: 01/31/2020 Accepted: 02/17/2020

Correspondence: Caleb Jensen, Augusta University, 1120 15 $5^{\text {th }}$ St. Augusta, GA 30912, cajensen@augusta.edu 


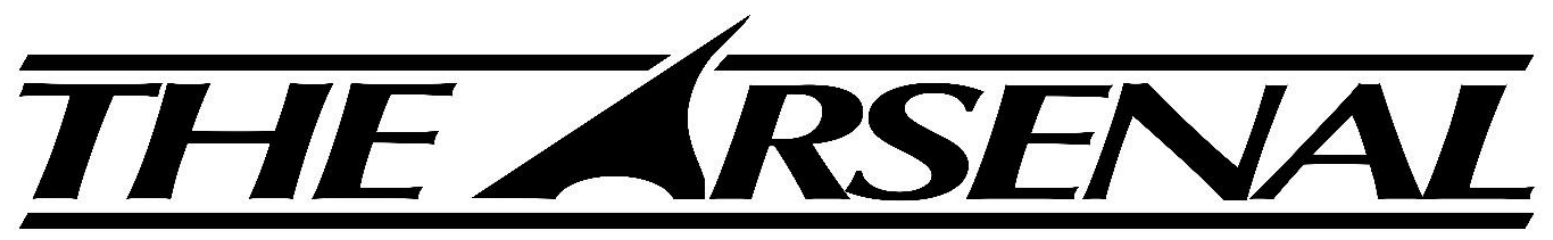

\section{Augusta University's Undergraduate Research Journal}

ISSN 2380-5064 | The Arsenal is published by the Augusta University Libraries | http://guides.augusta.edu/arsenal

Volume 3, Issue 2 (2020)

Special Edition Issue

\section{COMPETITIVE BALANCE IN WOMEN'S COLLEGIATE GOLF}

Austin Jones and Simon Medcalfe

\section{Citation}

Jones, A., \& Medcalfe, S. (2020). Competitive balance in women's collegiate golf. The Arsenal: The Undergraduate Research Journal of Augusta University, 3(2), http://doi.org/10.21633/issn.2380.5064/s.2020.03.02.21 


\title{
Competitive Balance in Women's Collegiate Golf
}

Presenter: Austin Jones (Poster Presentation)

Authors: Austin Jones and Simon Medcalfe

Faculty Sponsor(s): Simon Medcalfe, $\mathrm{PhD}$

Department Affiliation: Business

\begin{abstract}
Since the implementation of title IX in 1972, there has been in increase in the organization and participation of women's collegiate sports teams. In 1982, which is when women started competing in NCAA golf, participation was numbered at 739 and by 2008, there were a total of 2047 participants. This paper shows how the increase in participation amongst Division 1 women's golf teams has affected the competitive balance in women's collegiate golf. The method of assessing this effect is to compare all the participating scores in past NCAA championships against the increase in participation over time. It is hypothesized that as participation increased, the scores have trended lower and therefore made women's golf more competitive. The Division 1 men's golf teams are used as a control to see that the effects are unique to the women's teams.
\end{abstract}

Received: 01/31/2020 Accepted: 02/17/2020

Correspondence: Austin Jones, Augusta University, $112015^{\text {th }}$ St. Augusta, GA 30912, ausjones@ augusta.edu 


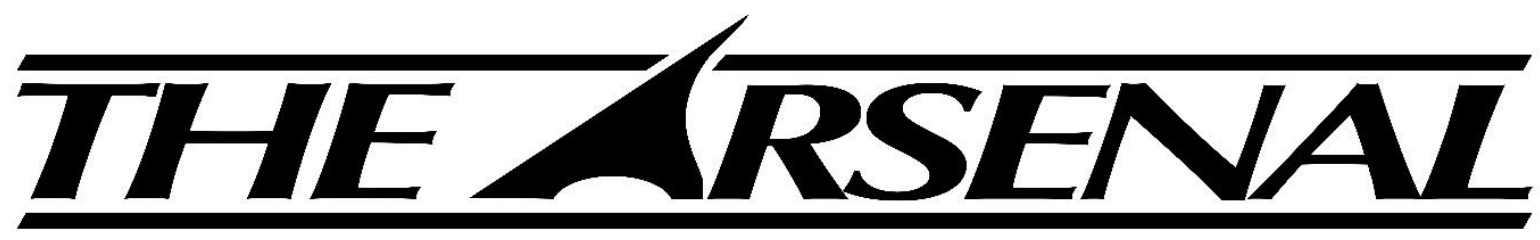

\section{Augusta University's Undergraduate Research Journal}

ISSN 2380-5064 | The Arsenal is published by the Augusta University Libraries | http://guides.augusta.edu/arsenal

Volume 3, Issue 2 (2020)

Special Edition Issue

\section{ASSESSING STUDENTS' SPATIAL ABILITIES IN NEUROANATOMY EDUCATION}

Arundhati Kumar, Tasha R. Wyatt, and Joanna R. Appel

\section{Citation}

Kumar, A., Wyatt, T. R., \& Appel, J. (2020). Assessing students' spatial abilities in neuroanatomy education. The Arsenal: The Undergraduate Research

Journal of Augusta University, 3(2), http://doi.org/10.21633/issn.2380.5064/s.2020.03.02.22 


\title{
Assessing Students' Spatial Abilities in Neuroanatomy Education
}

Presenter: Arundhati Kumar (Poster Presentation)

Authors: Arundhati Kumar'1, Tasha R. Wyatt ${ }^{2}$, and Joanna R. Appel ${ }^{2}$

Faculty Sponsor(s): Joanna R. Appel, PhD

Department Affiliation: ${ }^{1}$ Biological Sciences, ${ }^{2}$ Neuroscience \& Regenerative Medicine

Funding: Medical College of Georgia Academic Affairs

\begin{abstract}
Neuroanatomy requires students to acquire, assimilate, and apply knowledge of complex neuroanatomical structures. Three-dimensional (3D) physical models and computer-aided digital models are effective in promoting the development of neuroanatomical spatial representations. However, what remains unclear is exactly which tools benefit students the most. This study investigates whether there is a relationship between individuals' spatial abilities and their neuro-spatial knowledge, and to determine whether learning neuroanatomy is enhanced using one of three instructional tools. The spatial aptitude of undergraduate medical students enrolled in neuroanatomy was measured by tests previously validated as predictors of visual-spatial abilities, and a spatial aptitude profile was generated for each student. Students were given a pre-test designed to assess critical spatial skills within the context of applied-neuroanatomy. Following the pre-test, students attended a learning session where they interacted with one of three learning tools: a) 3D printed neuroanatomical models, b) 3D virtual neuroanatomical models, or c) hands-on deep-brain dissection. The effectiveness of each tool on student learning was evaluated by a post-test. Preliminarily, all three instructional tools proved effective when assessing percentage change in pre-test:post-test scores. Data is under analysis to determine if there exists an interplay between individual students' spatial abilities and the effectiveness of each learning tool.
\end{abstract}

Received: 01/31/2020 Accepted: 02/17/2020

Correspondence: Arundhati Kumar, Augusta University, 1120 15 $5^{\text {th }}$ St. Augusta, GA 30912, arukumar@augusta.edu 


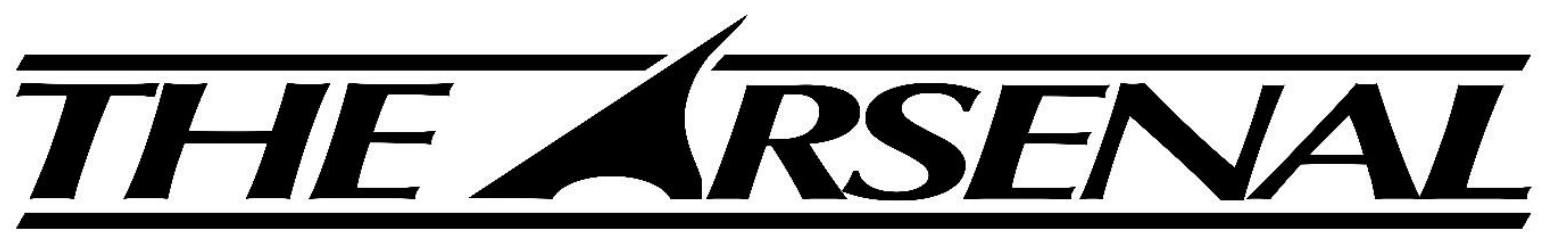

\section{Augusta University's Undergraduate Research Journal}

ISSN 2380-5064 | The Arsenal is published by the Augusta University Libraries | http://guides.augusta.edu/arsenal

Volume 3, Issue 2 (2020)

Special Edition Issue

\section{IONIC AND COVALENT CONJUGATES OF METRONIDAZOLE AND TRYPTAMINE}

Dominique Lyons, Precious Baako, and Iryna Lebedyeva

\section{Citation}

Lyons, D., Baako, P., \& Lebedyeva, J. (2020). Ionic and covalent conjugates of metronidazole and tryptamine. The Arsenal: The Undergraduate Research Journal of Augusta University, 3(2), http://doi.org/10.21633/issn.2380.5064/s.2020.03.02.23 


\title{
Ionic and Covalent Conjugates of Metronidazole and Tryptamine
}

Presenter: Dominique Lyons (Poster Presentation)

Authors: Dominique Lyons, Precious Baako, and Iryna Lebedyeva

Faculty Sponsor(s): Iryna Lebedyeva, $\mathrm{PhD}$

Department Affiliation: Chemistry and Physics

\begin{abstract}
Metronidazole is an antibiotic used in the treatment of many bacterial and parasitic infections. This antibacterial agent has been shown to have a variety of uses upon its development. Metronidazole is derived synthetically from Azomycin, a natural antimicrobial antibiotic produced by actinobacteria, such as Norcadia mesenterica and Sterptomyces eurocidicus, and proteobacteria such as Pseudomonas fluorescens used to treat anaerobic parasitic and bacterial infections. Solid drugs are not as effective in the body because they are not soluble enough to allow for effective release into circulation, which makes it hard for the body to absorb. However, ionic liquids can be used to improve drug delivery, efficacy, and development. Ionic liquid compositions are typically made up of at least two different ions with at least one kind of cation and one kind of anion. In this project, ionic liquid compositions containing metronidazole as a positively charged ion and acesulfame as a counterion have been synthesized. To explore the brain-penetrating ability of tryptamine, we have created its conjugates with beta-alanine, glucine, and gabapentin. These ionic and covalent conjugates represent existing drugs with improved properties such as palatability and lipophilicity.
\end{abstract}

Received: 01/31/2020 Accepted: 02/17/2020

Correspondence: Dominique Lyons, Augusta University, $112015^{\text {th }}$ St. Augusta, GA 30912, dolyons@augusta.edu 


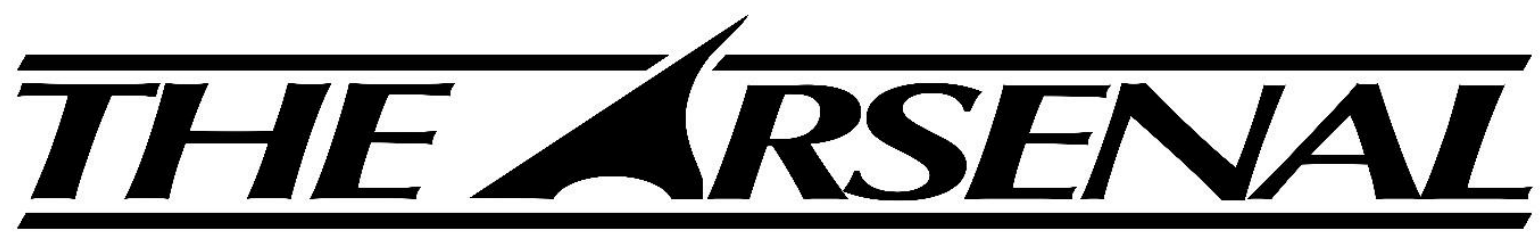

\title{
Augusta University's Undergraduate Research Journal
}

ISSN 2380-5064 | The Arsenal is published by the Augusta University Libraries | http://guides.augusta.edu/arsenal

Volume 3, Issue 2 (2020)

Special Edition Issue

\section{IMPACTS OF CULTURAL BARRIERS ON HEALTHCARE}

\author{
Eden Mahoney, Pamela Hayward, Wendy Turner, \\ Debra VanTuyll, and Herbert VanTuyll
}

\section{Citation}

Mahoney, E., Hayward, P., Turner, W., VanTuyll, D., \& VanTuyll, H. (2020).

Impacts of cultural barriers on healthcare. The Arsenal: The Undergraduate Research

Journal of Augusta University, 3(2), http://doi.org/10.21633/issn.2380.5064/s.2020.03.02.24 


\title{
Impacts of Cultural Barriers on Healthcare
}

Presenter: Eden Mahoney (Oral Presentation)

Authors: Eden Mahoney ${ }^{1}$, Pamela Hayward ${ }^{2}$, Wendy Turner ${ }^{3}$, Debra VanTuyl1 ${ }^{2}$, and Hubert VanTuyll ${ }^{3}$

Faculty Sponsor(s): Pamela Hayward, PhD, Wendy Turner, PhD, Debra VanTuyll, PhD, and Hubert VanTuyll, $\mathrm{PhD}$

Department Affiliation: ${ }^{1}$ Allied Health Sciences, ${ }^{2}$ Communication, ${ }^{3}$ History, Anthropology \& Philosophy

\begin{abstract}
Civil unrest and the emergence of terrorist groups have caused humanitarian crises in Middle Eastern countries that have led to an influx of Arab refugees and asylum seekers to the United States. This paper explores both the causes and effects of cultural differences and discrimination on healthcare outcomes for Middle Eastern patients in Western cultures. Relationships between Middle Eastern patients and Western health care providers are often plagued by mutual misunderstanding of culturally influenced values, including contrasting views of family roles in medicine, communication styles, religious beliefs, and attitudes regarding preventative care and illness. These cultural differences combined with increased systemic discrimination since $9 / 11$ have not only created barriers in access to healthcare, but have intensified the need for healthcare in Middle Eastern populations who exhibit higher premature birth rates, increased prevalence of mental health disorders, and chronic health conditions including PTSD, hypertension, and diabetes, as well as decreased screening and vaccination rates compared to white Americans. The key to bridging the cultural gap between Western medicine and Arab patients and providing quality healthcare that will improve rather than impede their healthcare lies in cultural understanding through education, relationship-building, and respect.
\end{abstract}




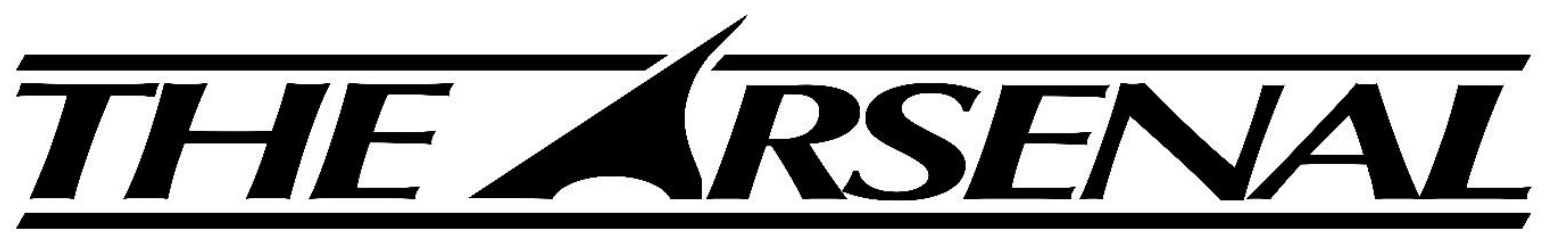

\section{Augusta University's Undergraduate Research Journal}

ISSN 2380-5064 | The Arsenal is published by the Augusta University Libraries | http://guides.augusta.edu/arsenal

Volume 3, Issue 2 (2020)

Special Edition Issue

\section{CAN FAST FASHION BE SUSTAINABLE AND STILL BE PROFITABLE?}

Eva Miralles Miro and Simon Medcalfe

\section{Citation}

Miro, E. M., \& Medcalfe, S. (2020). Can fast fashion be sustainable and still be profitable? The Arsenal: The Undergraduate Research Journal of Augusta University, 3(2), http://doi.org/10.21633/issn.2380.5064/s.2020.03.02.25 


\title{
Can Fast Fashion Be Sustainable and Still Be Profitable?
}

Presenter: Eva Miralles Miro (Poster Presentation)

Authors: Eva Miralles Miro and Simon Medcalfe

Faculty Sponsor(s): Simon Medcalfe, $\mathrm{PhD}$

Department Affiliation: Business

\begin{abstract}
Fast fashion is the approach to designing, creating, and marketing clothing that emphasizes making fashion trends quickly and available to consumers. It is destroying the world we live in, creating a big opportunity cost for society, because it is the second largest polluter after the oil industry. Can the giants of fast fashion keep earning the amount of money they earn if they start complying with the best environmental regulations and sustainable practices? Economic theory suggests that if consumers demand higher ethical practices from fashion companies then profits will rise. However, if these practices increase costs then profits will fall. The 2019 Ethical Fashion Report published by Baptist World Aid Australia gives grades to 130 fashion companies according to five different ethical management practices. This data is used to determine how fashion companies' profits vary with different metrics of ethic and sustainable practices and which have the biggest impact on profit.
\end{abstract}




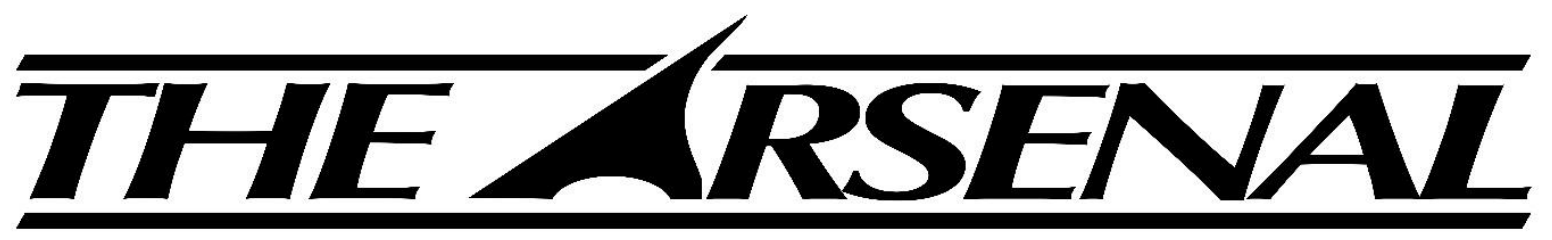

\section{Augusta University's Undergraduate Research Journal}

ISSN 2380-5064 | The Arsenal is published by the Augusta University Libraries | http://guides.augusta.edu/arsenal

Volume 3, Issue 2 (2020)

Special Edition Issue

\section{CHARACTERIZATION OF PROTEIN SENSITIVE G PROTEIN-COUPLED RECEPTORS}

Alisha Nam, Najeah Okashah, Angela Spencer, and Nevin Lambert

\section{Citation}

Nam, A., Okashah, N., Spencer, A., \& Lambert, N. (2020). Characterization of protein sensitive $\mathrm{G}$ protein-coupled receptors. The Arsenal: The Undergraduate Research Journal of Augusta University, 3(2), http://doi.org/10.21633/issn.2380.5064/s.2020.03.02.26 


\title{
Characterization of Protein Sensitive G-Protein Coupled Receptors
}

Presenter: Alisha Nam (Poster Presentation)

Authors: Alisha Nam ${ }^{1}$, Najeah Okashah ${ }^{2}$, Angela Spencer ${ }^{3}$, and Nevin Lambert ${ }^{2}$

Faculty Sponsor(s): Angela Spencer, $\mathrm{PhD}$ and Nevin Lambert, $\mathrm{PhD}$

Department Affiliation: ${ }^{1}$ Biological Sciences, ${ }^{2}$ Pharmacology \& Toxicology, ${ }^{3}$ Chemistry \& Physics

Funding: Augusta University CURS Student Research Grant, NIH grant GM130142 to Lambert

\begin{abstract}
G protein-coupled receptors (GPCRs) are membrane-bound receptors that can stimulate an intracellular signaling pathway following activation by a ligand. According to the International Union of Basic and Clinical Pharmacology (IUPHAR) database, GPR4, GPR65, and GPR132 are Class A orphan GPCRs with protons reported as their putative endogenous ligand; however, these receptors are currently understudied. After confirming whether these receptors are $\mathrm{pH}$-sensitive, the purpose of our study was to investigate the interactions between GPR4, GPR65, GPR132, and $G$ protein subtypes $\left(\mathrm{G} \alpha_{\mathrm{s}}, \mathrm{G} \alpha_{\mathrm{i}}, \mathrm{G} \alpha_{\mathrm{q}}\right.$, and $\mathrm{G} \alpha_{12}$ ) upon stimulation with an acidic solution. Using bioluminescence resonance energy transfer (BRET), we studied the coupling between luciferase-tagged GPR receptors and fluorescent protein (Venus)-tagged $\mathrm{G}$ proteins in response to $\mathrm{pH}$ changes. Data indicated that all three receptors responded to $\mathrm{pH}$ changes. Upon extracellular response to $\mathrm{pH}$ changes, the receptors activate different $\mathrm{G}$ protein subtypes and thus, different signaling pathways: GPR4 activates $\mathrm{G} \alpha_{\mathrm{i}}, \mathrm{G} \alpha_{\mathrm{q}}$, and $\mathrm{G} \alpha_{12}$; GPR65 activates all four subtypes; and GPR132 activates $G \alpha_{i}$ and weakly activates $G \alpha_{q}$, and $G \alpha_{12}$. Identifying these receptors as true proton sensors leads the way in understanding the role they play in maintaining acidbase homeostasis and will be critical for the development of novel drugs combatting acidbase related disorders.
\end{abstract}

Received: 01/31/2020 Accepted: 02/17/2020

Correspondence: Alisha Nam, Augusta University, 1120 15 $5^{\text {th }}$ St. Augusta, GA 30912, anam@augusta.edu 


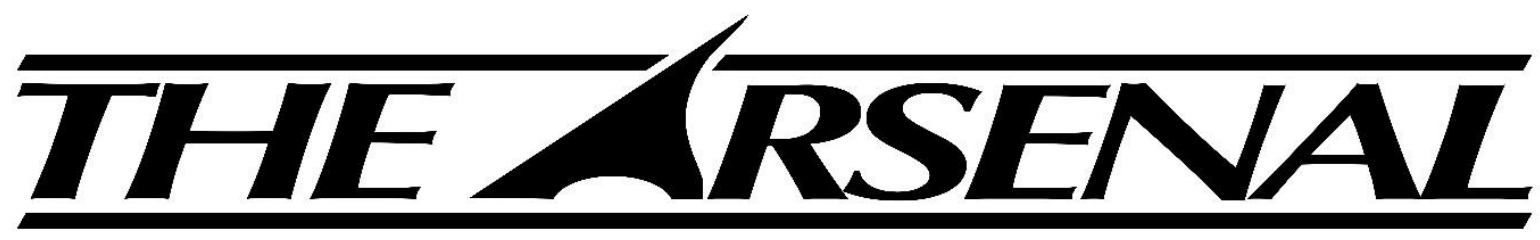

\section{Augusta University's Undergraduate Research Journal}

ISSN 2380-5064 | The Arsenal is published by the Augusta University Libraries | http://guides.augusta.edu/arsenal

Volume 3, Issue 2 (2020)

Special Edition Issue

\section{LGBTQ+ COLLEGE STUDENTS' WELL-BEING AND PHYSICAL ACTIVITY}

\section{Dalanie Nix and Hannah Bennett}

\section{Citation}

Nix, D., \& Bennett, H. (2020). LGBTQ+ college students' well-being and physical activity. The Arsenal: The Undergraduate Research Journal of Augusta University, 3(2), http://doi.org/10.21633/issn.2380.5064/s.2020.03.02.27 


\section{LGBTQ+ College Students' Well-being and Physical Activity}

Presenter: Dalanie Nix (Oral Presentation)

Authors: Dalanie Nix and Hannah Bennett

Faculty Sponsor(s): Hannah Bennett, $\mathrm{PhD}$

Department Affiliation: Kinesiology

\section{ABSTRACT}

Many college students experience a downswing in mental well-being once beginning college. Studies have shown that the mental well-being of many college students are negatively impacted by alcohol consumption, cigarette use, and lower grades. Along with those factors, poor sleep habits are also linked to poor performance and overall well-being of students. LGBTQ+ college students experience discriminatory stressors, such as bullying, compounded with the stressors of college life which can lead to increased rates of anxiety, depression, and suicidal thoughts. Physical activity has been shown to improve well-being and depression symptoms. It has also been proven to be as effective as psychological and drug therapies. Many LGBTQ+ college students are turned away from sports due to LGBTQ+ cultural norms, as well as bullying from peers. This project employed a case study narrative approach of LGBTQ+ college students. 5 participants, ranging from 18-21 years of age and various sexual orientations, were interviewed about how physical activity has affected their well-being. We predict that LGBTQ+ college students who participate in regular physical activity will express lower levels of anxiety and depression along with greater levels of well-being. 


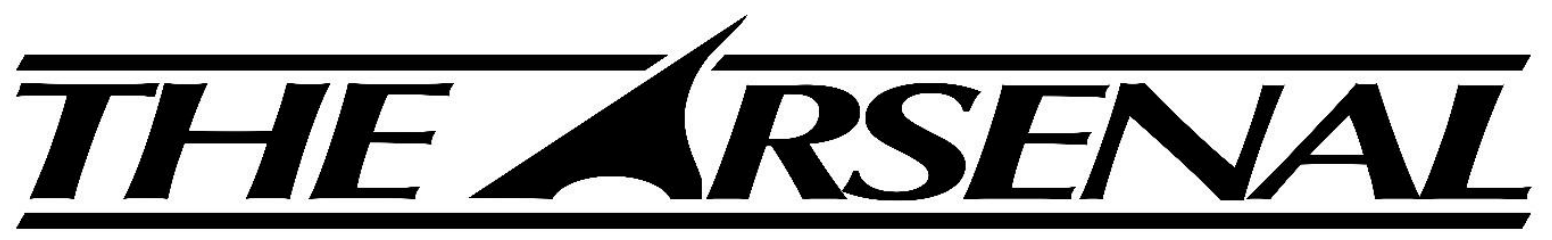

Augusta University's Undergraduate Research Journal

ISSN 2380-5064 | The Arsenal is published by the Augusta University Libraries | http://guides.augusta.edu/arsenal

Volume 3, Issue 2 (2020)

Special Edition Issue

DIABETES ATTENUATION OF THE ESTROGEN-

MEDIATED INCREASE IN ENDOTHELIAL FUNCTION

IS ASSOCIATED WITH CIRCULATING SIRT1

Sinead O’Bryant, Casey Derella, Jeff Thomas, Jacob Looney, Marie-Rose Bieck, and Ryan A. Harris

\section{Citation}

O’Bryant, S., Derella, C., Thomas, J., Looney, J., Bieck, M., \& Harris, R. A. (2020).

Diabetes attenuation of these estrogen-mediated increase in endothelial function is associated with circulating SIRT1. The Arsenal: The Undergraduate Research Journal of Augusta University, 3(2), http://doi.org/10.21633/issn.2380.5064/s.2020.03.02.28

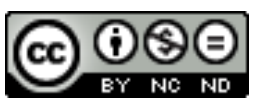

(C) Bryant et al. 2020. This open access article is distributed under a Creative Commons Attribution NonCommercial-NoDerivs 2.0 Generic License (https://creativecommons.org/licenses/by-nc-nd/2.0/). 


\section{Diabetes Attenuation of the Estrogen-Mediated Increase in Endothelial Function is Associated with Circulating SIRT1}

Presenter: Sinead O'Bryant (Oral Presentation)

Authors: Sinead O'Bryant ${ }^{1}$, Casey Derella ${ }^{2}$, Jeff Thomas ${ }^{2}$, Jacob Looney ${ }^{2}$, Marie-Rose Bleck ${ }^{2}$, and Ryan A. Harris ${ }^{2}$

Faculty Sponsor(s): Ryan A. Harris, $\mathrm{PhD}$

Department Affiliation: ${ }^{1}$ Biological Sciences, ${ }^{2}$ Georgia Prevention Institution

Funding: NIH

\section{ABSTRACT}

Cardiovascular disease (CVD) is the most prominent killer within Type 1 Diabetes (T1D) with endothelial dysfunction as a major player in the development of CVD. Women with T1D experience an accelerated CVD risk despite the apparent sex-specific cardioprotection from circulating endogenous estrogen experienced by heathy pre-menopausal women. Animal models have shown the modulation of SIRT1, a NAD+ histone deacetylase, by estrogen as a CVD protector. This study sought to test the hypothesis that lower circulating SIRT1 is associated with reduced endothelial function in T1D women. Change in flow mediated dilation (FMD), a clinical measure of endothelial function, and SIRT1 over the menstrual cycle exhibited contrasting trends between T1D women and healthy women: increases of FMD and SIRT1 as estrogen increases in healthy women and decreases of FMD and SIRT1 as estrogen increases in T1D women. This provides evidence that signaling roles by circulating estrogen may be attenuated in T1D and that the effects of decreased SIRT1 contributes to endothelial dysfunction, resulting in determinant effects on vascular health in T1D women. 


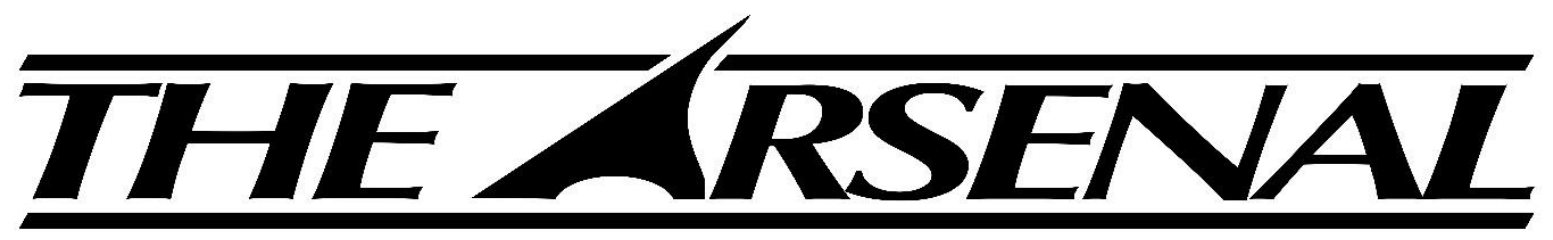

Augusta University's Undergraduate Research Journal

ISSN 2380-5064 | The Arsenal is published by the Augusta University Libraries | http://guides.augusta.edu/arsenal

Volume 3, Issue 2 (2020)

Special Edition Issue

DEVELOPMENTAL BIOLOGY OF ZEBRAFISH AND INTEGRATION OF TRANSGENIC LINES TO STUDY MICROGLIA IN PERSPECTIVE OF GLIOBLASTOMA

Anabelle O’Keefe, Katherine McCartney, Umasai Kandepu,
and Surendra Rajpurohit

\section{Citation}

O’Keefe, A., McCartney, K., Kandepu, U., \& Rajpurohit, S. (2020). Developmental biology of zebrafish and integration of transgenic lines to study microglia in perspective of glioblastoma. The Arsenal: The Undergraduate Research Journal of Augusta University, 3(2), http://doi.org/10.21633/issn.2380.5064/s.2020.03.02.29

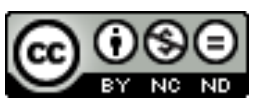

(C) O'Keefe, McCartney, Kandepu, Rajpurohit 2020. This open access article is distributed under a Creative Commons Attribution NonCommercial-NoDerivs 2.0 Generic License (https://creativecommons.org/licenses/by-nc-nd/2.0/). 


\title{
Developmental Biology of Zebrafish and Integration of Transgenic Lines to Study Microglia in Perspective of Glioblastoma
}

Presenter: Anabelle O’Keefe (Oral Presentation)

Authors: Anabelle O'Keefe ${ }^{1}$, Katherine McCartney ${ }^{1}$, Umasai Kandepu ${ }^{1}$, and Surendra Rajpurohit ${ }^{2}$

Faculty Sponsor(s): Surendra Rajpurohit, $\mathrm{PhD}$

Department Affiliation: ${ }^{1}$ Biological Sciences, ${ }^{2}$ Biochemistry and Molecular Biology

Funding: Augusta University CURS Summer Scholars Program, CURS Student Research Grant and SGA

\begin{abstract}
Glioblastoma is a vicious cancer of the brain that is extremely invasive. Our innovative approach to studying glioblastoma utilizes zebrafish as the model for scientific study because of their affordable maintenance, transparent body plan during embryo and larval stages, and genomic accessibility. We aim to use zebrafish as an organismal model to study how glioblastoma and microglial cells interact in the neural region. To achieve this, we are developing an all-encompassing in-vivo transgenic and transparent zebrafish modeling system to study microglia function and manipulation in the context of adverse conditions such as glioblastoma and inflammation. Microglia are the resident macrophages found in zebrafish and humans located along the central nervous system in the brain and spinal cord. These cells support the immune system by cleaning any foreign andebris. The model will integrate Microglia, NF-kB, and Annexin-5 transgenic lines, displaying which genes in the brain are activated via their corresponding fluorescent protein upon the introduction of glioblastoma. Furthermore, a mutant Casper line of zebrafish will introduce a transparent characteristic in adult zebrafish which allows for simpler visualization and observation in the final model. Ultimately, this transgenic model will utilize microglia cells as a mechanism to approach glioblastomas.
\end{abstract}

Received: 01/31/2020 Accepted: 02/17/2020

Correspondence: Anabelle O'Keefe, Augusta University, 1120 15 ${ }^{\text {th }}$ St. Augusta, GA 30912, anokeefe@ augusta.edu 


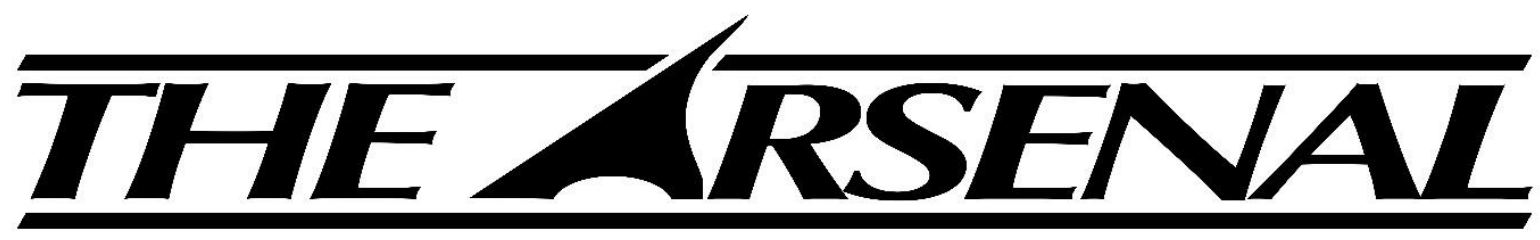

\title{
Augusta University's Undergraduate Research Journal
}

ISSN 2380-5064 | The Arsenal is published by the Augusta University Libraries | http://guides.augusta.edu/arsenal

Volume 3, Issue 2 (2020)

Special Edition Issue

\section{UNCONSCIOUSLY IN THE CLOSET: REPRESSED QUEERNESS IN ANOTHER COUNTRY}

\author{
Alison O'Keefe and Todd Hoffman
}

\section{Citation}

O'Keefe, A., \& Hoffman, T. (2020). Unconsciously in the closet: Repressed queerness in another country. The Arsenal: The Undergraduate Research Journal of Augusta University, 3(2), http://doi.org/10.21633/issn.2380.5064/s.2020.03.02.30 


\title{
Unconsciously in the Closet: Repressed Queerness in Another Country
}

Presenter: Alison O’Keefe (Oral Presentation)

Authors: Alison O'Keefe and Todd Hoffman

Faculty Sponsor(s): Todd Hoffman, $\mathrm{PhD}$

Department Affiliation: English and Foreign Languages

\begin{abstract}
When analyzed through the lenses of queer theory and Freudian psychoanalysis, James Baldwin's novel Another Country becomes a study of the male homosocial continuum, repressed queerness, and defense mechanisms. The character Rufus Scott encapsulates repressed male homosexual desire, especially with respect to his closest friend, Vivaldo. This presentation will explore how the male homosocial continuum is disrupted and the psychological consequences of this disruption on queer men through Rufus's actions, particularly when they are considered in the context of his relationship with Vivaldo. Due to the aforementioned disruption, Rufus idealizes heterosexuality. Consequently, he represses his queerness, which results in reaction formation, causing him to act as if he is straight, as well as displacement, causing him to place his sexual feelings and anger towards Vivaldo towards his girlfriend, Leona. These defense mechanisms manifest in an erotic triangle between the three through which the two men communicate their desire for each other. Although Rufus is dead for a substantial portion of the novel, his influence lives on through the characters who survive him, so his emotions and behaviors during his life are of critical importance.
\end{abstract}

Received: 01/31/2020 Accepted: 02/17/2020

Correspondence: Alison O'Keefe, Augusta University, $112015^{\text {th }}$ St. Augusta, GA 30912, aokeefe@ augusta.edu 


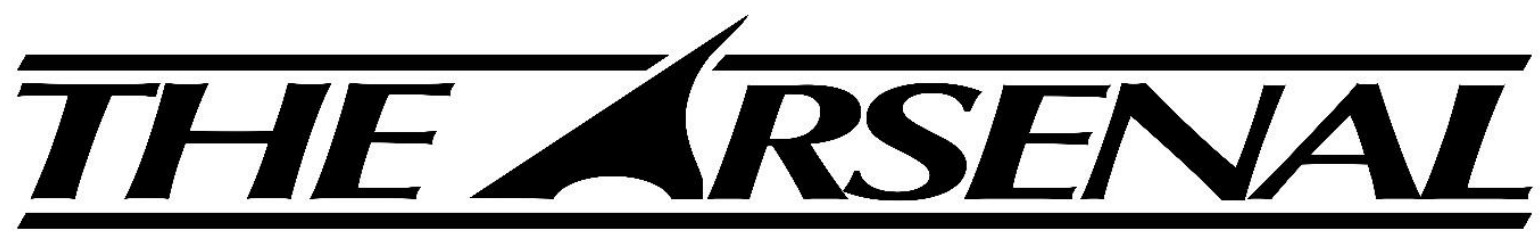

\title{
Augusta University's Undergraduate Research Journal
}

ISSN 2380-5064 | The Arsenal is published by the Augusta University Libraries | http://guides.augusta.edu/arsenal

Volume 3, Issue 2 (2020)

Special Edition Issue

\section{MINIMUM FLOW RATE IN ELECTRO-COFLOW}

\author{
Benjamin Overlie and Josefa Guerrero-Millan
}

\section{Citation}

Overlie, B., \& Guerrero-Millan, J. (2020). Minimum flow rate in electro-coflow.

The Arsenal: The Undergraduate Research Journal of Augusta University, 3(2), http://doi.org/10.21633/issn.2380.5064/s.2020.03.02.31 


\title{
Minimum Flow Rate in Electro-Coflow
}

Presenter: Benjamin Overlie (Oral Presentation)

Authors: Benjamin Overlie and Josefa Guerrero-Millan

Faculty Sponsor(s): Josefa Guerrero-Millan, $\mathrm{PhD}$

Department Affiliation: Chemistry and Physics

Funding: ACS Petroleum Research Fund (60302-UR9)

\begin{abstract}
Controlled generation of micron and sub-micron sized drops continues to be of strong interest for the scientific community due to the variety of applications in many different fields. Emulsion drops can be generated by flowing two immiscible liquids inside a glassbased microfluidic device. Their minimum size will be of the order of the tip size. To create smaller drops, an external electric field can be used, similarly to what it is done in the classical electrospray. In electrospray, a liquid is issued into the air from an electrified needle. When the flow rate of the liquid is controlled, there is a minimum flow rate below which a cone-jet cannot be formed regardless of the applied voltage. This minimum flow rate provides the minimum drop size that can be generated, usually one or two orders of magnitude smaller than the tip size. In this presentation, we explore this lower limit in electro-coflow using pressure control instead, which generates different results from using electrospray, and with a more complex behavior. The use of pressure control, and the presence of an outer moving fluid, enrich the dynamics in the minimum flow rate limit.
\end{abstract}

Received: 01/31/2020 Accepted: 02/17/2020

Correspondence: Benjamin Overlie, Augusta University, $112015^{\text {th }}$ St. Augusta, GA 30912, boverlie@augusta.edu 


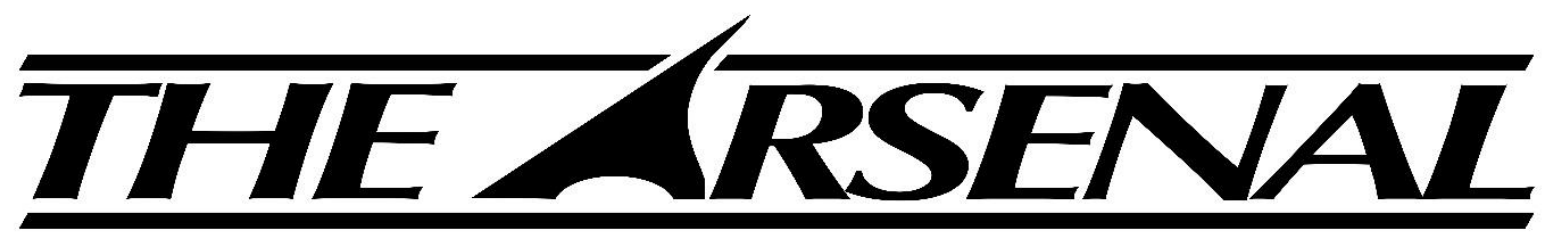

\section{Augusta University's Undergraduate Research Journal}

ISSN 2380-5064 | The Arsenal is published by the Augusta University Libraries | http://guides.augusta.edu/arsenal

Volume 3, Issue 2 (2020)

Special Edition Issue

\section{THE EVOLUTION OF ART THERAPY AND PROPOSED FUTURE APPLICATION}

Connor Owen and Edgar Johnson

\section{Citation}

Owen, C., \& Johnson, E. (2020). The evolution of art therapy and proposed future application. The Arsenal: The Undergraduate Research Journal of Augusta University, 3(2), http://doi.org/10.21633/issn.2380.5064/s.2020.03.02.32 


\title{
The Evolution of Art Therapy and Proposed Future Application
}

Presenter: Connor Owen (Poster Presentation)

Authors: Connor Owen ${ }^{1}$ and Edgar Johnson ${ }^{2}$

Faculty Sponsor(s): Edgar Johnson, $\mathrm{PhD}$

Department Affiliation: ${ }^{1}$ Art and Design, ${ }^{2}$ Communications

\begin{abstract}
The goal of this thesis is to describe the evolution of art therapy into the practice it is today and propose a future alternative use. Currently, art therapy is applied to a variety of populations and purposes with abundant research to support its efficacy; however, there is a gap in research on art therapy for college-aged students. Art therapy may be a viable alternative stress-management tool for mental health providers on college campuses, which could mean more participation from students in the available counseling resources and ultimately a reduction in the likelihood of students reaching a crisis. By analyzing prior research on art therapy for other populations, this thesis offers justification for its future use on the college campus.
\end{abstract}

Received: 01/31/2020 Accepted: 02/17/2020

Correspondence: Connor Owen, Augusta University, $112015^{\text {th }}$ St. Augusta, GA 30912, coowen@ augusta.edu 


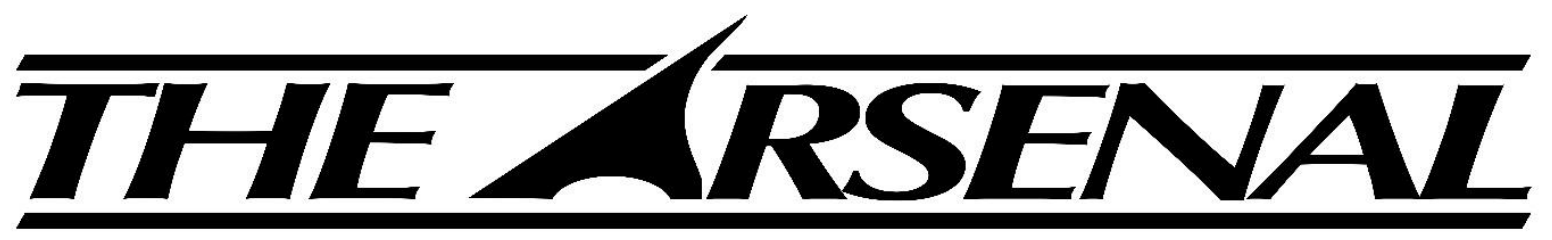

\section{Augusta University's Undergraduate Research Journal}

ISSN 2380-5064 | The Arsenal is published by the Augusta University Libraries | http://guides.augusta.edu/arsenal

Volume 3, Issue 2 (2020)

Special Edition Issue

\section{THE APPLICATION OF LOW-COST, CLOSE-RANGE PHOTOGRAMMETRY IN DENTISTRY}

Mohit Patel, D. Mettenburg, and F.A. Rueggeberg

\section{Citation}

Patel, M., Mettenburg, D., \& Rueggeberg, F. A. (2020). The application of low-cost, close-range photogrammetry in dentistry. The Arsenal: The

Undergraduate Research Journal of Augusta University, 3(2), http://doi.org/10.21633/issn.2380.5064/s.2020.03.02.33 


\title{
The Application of Low-Cost, Close-Range Photogrammetry in Dentistry
}

Presenter: Mohit Patel (Poster Presentation)

Authors: Mohit Patel ${ }^{1}$, D. Mettenburg ${ }^{2}$, and F.A. Rueggeberg ${ }^{2}$

Faculty Sponsor(s): F.A. Rueggeberg, DDS

Department Affiliation: ${ }^{1}$ Biological Sciences, ${ }^{2}$ Restorative Sciences

\begin{abstract}
Currently, three-dimensional scanning is required by a number of procedures in dentistry: Orthodontics, Prosthodontics, Endodontics, Oral Surgery, and General Restorative Dentistry. Close-Range Photogrammetry is a technique that produces three-dimensional coordinates of points identified from multiple images of an object taken at different angles. This technique may provide a low-cost alternative to expensive intra-oral scanning systems and structured light-based 3D scanners. The objective of this proof-of-concept project was to evaluate the accuracy and precision of virtual 3D models created using a low cost 3D-printable, open source, 3D scanner (OpenScan) connected to an Adreno controller, Agisoft Metashape software, and a budget smartphone used as a camera. A 3D printed set of teeth were scanned using the system and were also manually measured for comparison. A layer of wax was applied to a region on the teeth on the model and a second scan was obtained. The volume of wax coating was calculated using software and compared to measurements taken by hand. The two values were found to be quite similar, proving these initial attempts at accurately scanning dental models were viable for further development.
\end{abstract}

Received: 01/31/2020 Accepted: 02/17/2020 MOHPATEL

Correspondence: Mohit Patel, Augusta University, $112015^{\text {th }}$ St. Augusta, GA 30912, mohpatel@augusta.edu 


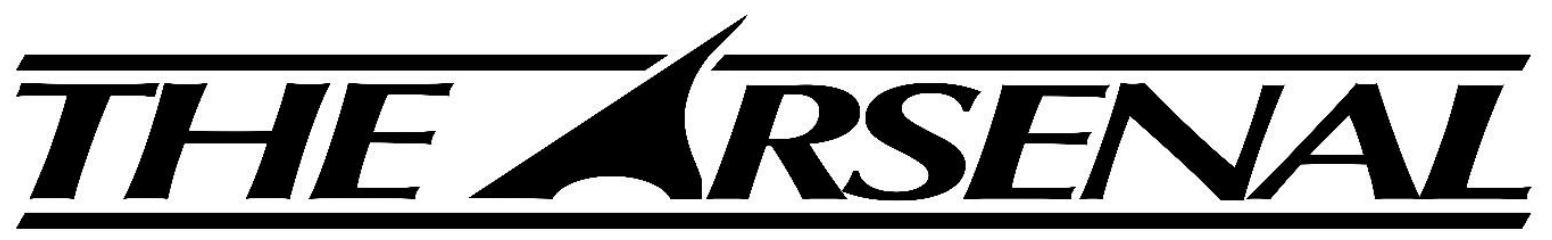

\section{Augusta University's Undergraduate Research Journal}

ISSN 2380-5064 | The Arsenal is published by the Augusta University Libraries | http://guides.augusta.edu/arsenal

Volume 3, Issue 2 (2020)

Special Edition Issue

\section{SALTY OR SLIGHTLY SALTY: IS FISH SPECIES RICHNESS AFFECTED BY AN OBSOLETE NAVIGATIONAL CUT?}

Rebecca Patterson, Loren Mathews, Bruce Saul, and Jessica Reichmuth

\section{Citation}

Patterson, R., Mathews, L., Saul, B., \& Reichmuth, J. (2020). Salty or slightly

salty: Is fish species richness affected by an obsolete navigational cut? The Arsenal: The Undergraduate Research Journal of Augusta University, 3(2), http://doi.org/10.21633/issn.2380.5064/s.2020.03.02.34 


\section{Salty or Slightly Salty: Is Fish Species Richness Affected by an Obsolete Navigational Cut?}

Presenter: Rebecca Patterson (Poster Presentation)

Authors: Rebecca Patterson ${ }^{1}$, Loren Mathews ${ }^{2}$, Bruce Saul ${ }^{1}$, and Jessica Reichmuth ${ }^{1}$

Faculty Sponsor(s): Jessica Reichmuth, $\mathrm{PhD}$

Department Affiliation: ${ }^{1}$ Biology Sciences (Augusta University), ${ }^{2}$ Biology (Georgia Southern University)

Funding: GADNR Coastal Resources Division Coastal Incentive Grant

\section{ABSTRACT}

As rivers flow toward the coast, freshwater mixes with saltwater in estuaries. The mixing here creates a wide range of environments for many organisms. The Satilla River Estuary has been cut eight times, which has altered the salinity gradients that are a result of natural tidal flow. Altered salinity gradients pose a threat to migratory fish species because they are no longer able to pick up on directional cues that these gradients provide, ultimately affecting species richness in the estuary. The purpose of this study is to determine if Noyes Cut has affected salinity gradients at five collection sites in Umbrella and Dover Creeks. Experimental gill nets were set one hour before max flood tide and soaked for two hours. All fish were identified to species with total and fork lengths measured to the nearest centimeter. Noyes Cut and Parsons Creek had the most species richness while River Marsh Landing and Todd Creek experienced the lowest diversity. We believe these large salinity fluctuations are due to a sediment deposit that blocks water flow as a result of Noyes Cut. When Noyes Cut is closed, we expect fish to redistribute into Umbrella and Dover Creeks as a result of restored salinity gradients.

Received: 01/31/2020 Accepted: 02/17/2020 REPATTERSON

Correspondence: Rebecca Patterson, Augusta University, $112015^{\text {th }}$ St. Augusta, GA 30912, repatterson@augusta.edu 


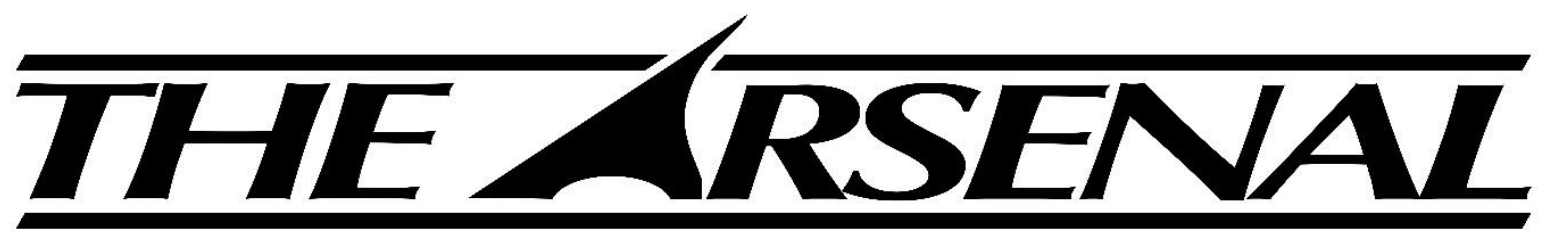

\section{Augusta University's Undergraduate Research Journal}

ISSN 2380-5064 | The Arsenal is published by the Augusta University Libraries | http://guides.augusta.edu/arsenal

Volume 3, Issue 2 (2020)

Special Edition Issue

\section{STRESS COPING MECHANISM AND THE EFFECTS OF ACADEMIC STRESS}

Erin Quick and William Bryant

\section{Citation}

Quick, E., \& Bryant, W. (2020). Stress coping mechanism and the effects of academic stress. The Arsenal: The Undergraduate Research Journal of Augusta University, 3(2), http://doi.org/10.21633/issn.2380.5064/s.2020.03.02.35 


\title{
Stress Coping Mechanism and the Effects of Academic Stress
}

Presenter: Erin Quick (Oral Presentation)

Authors: Erin Quick ${ }^{1}$ and William Bryant ${ }^{2}$

Faculty Sponsor(s): William Bryant, $\mathrm{PhD}$

Department Affiliation: ${ }^{1}$ Education, ${ }^{2}$ Communications

\begin{abstract}
Although stress and its effects on students are well-researched, stress-coping mechanisms themselves have not been fully explained and advocated for in young adults. Recent studies have shown that millennials display the highest recorded levels of stress, which is directly correlated with declining mental health. Effective stress-coping mechanisms can benefit individuals by offering methods to deal with overwhelming stress. Research offers three stress-reduction methods: Problem-Focused coping, Emotion-Focused coping, and Avoidance-Coping. These combat stress by providing effective strategies to manage and reduce stress levels. This presentation identifies what each method is and how each can be applied to environmental stressors, exploring how effective stress-coping mechanisms can reduce academic stress and further improve individuals' quality of life.
\end{abstract}

Received: 01/31/2020 Accepted: 02/17/2020

Correspondence: Erin Quick, Augusta University, $112015^{\text {th }}$ St. Augusta, GA 30912, erquick@ augusta.edu 


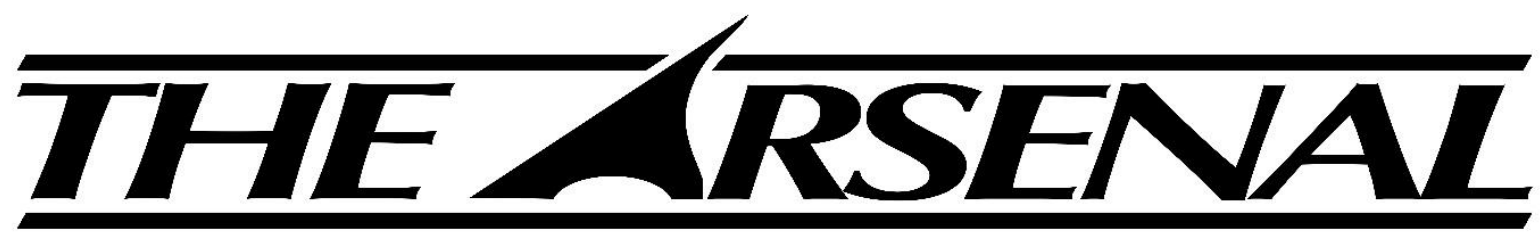

\section{Augusta University's Undergraduate Research Journal}

ISSN 2380-5064 | The Arsenal is published by the Augusta University Libraries | http://guides.augusta.edu/arsenal

Volume 3, Issue 2 (2020)

Special Edition Issue

\section{DELUSIONAL DISORDER IN THE NARRATOR OF MAUD}

\section{Havilah Ravula and Tim Sadenwasser}

\section{Citation}

Ravula, H., \& Sadenwasser, T. (2020). Delusional disorder in the narrator of Maud.

The Arsenal: The Undergraduate Research Journal of Augusta University, 3(2), http://doi.org/10.21633/issn.2380.5064/s.2020.03.02.36 


\section{Delusional Disorder in the Narrator of Maud}

Presenter: Havilah Ravula (Oral Presentation)

Authors: Havilah Ravula ${ }^{1}$ and Tim Sadenwasser ${ }^{2}$

Faculty Sponsor(s): Tim Sadenwasser, $\mathrm{PhD}$

Department Affiliation: ${ }^{1}$ College of Science and Mathematics, ${ }^{2}$ English and Foreign Languages

\section{ABSTRACT}

Alfred Tennyson's poem, Maud, was written from the perspective of a narrator madly in love with the titular character. The narrator goes through different phases throughout the text during which his interpretations of his surroundings, including his natural and relational environments, change with each passing event. During these changes, the narrator exhibits symptoms of mental disorders, including PTSD, bipolar disorder, and various delusional disorders. The narrator's depressive yet frenzied moods and his obsessive thoughts, the majority of which point to delusional disorder evident in the erotomaniac and persecutory types, begin to push him towards insanity. This presentation aims to delve into each of the symptoms of the narrator and how his delusions distort his interpretations of his relationships. An analysis of the text shows multiple instances in which the narrator shares his intense feelings. The narrator has been scarred by his father's death to such an extent that the beauty of nature around him morphs into a disfigured, bleeding landscape. He loves Maud obsessively; he will do almost anything to be with her. Finally, he loathes her brother for obstructing his relationship with Maud. Eventually, his delusions leave him a tormented individual who cannot find respite from his troubled mind. 


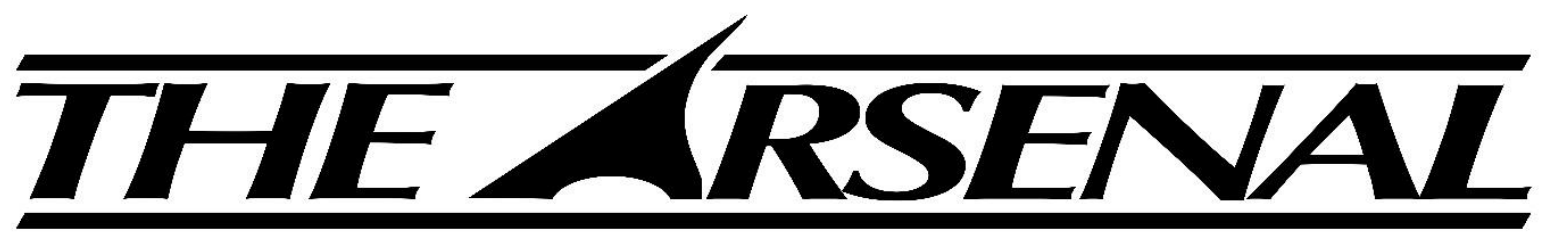

\title{
Augusta University's Undergraduate Research Journal
}

ISSN 2380-5064 | The Arsenal is published by the Augusta University Libraries | http://guides.augusta.edu/arsenal

Volume 3, Issue 2 (2020)

Special Edition Issue

\section{FEASIBILITY OF REUSABLE RADIOCHROMIC PLASTICS AS DOSIMETER}

\author{
Maxwell Recht, Chase Inglett, Joseph Newton, \\ Joseph Hauger, and John Adamovics
}

\section{Citation}

Recht, M., Inglett, C., Newton, J., Hauger, J., \& Adamovics, J. (2020). Feasibility of reusable radiochromic plastics as dosimeter. The Arsenal: The Undergraduate Research Journal of Augusta University, 3(2), http://doi.org/10.21633/issn.2380.5064/s.2020.03.02.37 


\title{
Feasibility of Reusable Radiochromic Plastics as Dosimeter
}

Presenter: Maxwell Recht (Oral Presentation)

Authors: Maxwell Recht ${ }^{1}$, Chase Inglett ${ }^{2}$, Joseph Newton ${ }^{2}$, Joseph Hauger ${ }^{2}$, and John Adamovics ${ }^{3}$

Faculty Sponsor(s): Joseph Newton, $\mathrm{PhD}$

Department Affiliation: ${ }^{1}$ Biological Sciences, ${ }^{2}$ Chemistry and Physics, ${ }^{3}$ Rider University

\begin{abstract}
New and improved developments in the field of radiotherapy have created extremely effective and efficient procedures for the treatment of tumors. Such developments require complex radiotherapy systems and plans which have ultimately improved the successfulness of treatments and improved the options available to patients. However, these advanced treatments present challenges for current dosimetric verification techniques which struggle to keep up. We will be examining radiochromic plastics as a way of addressing this conflict. Radiochromic plastics are synthetic materials whose optical properties change upon absorption of dose. The color darkens when the dose is absorbed, and the change in optical density is proportional to the dose absorbed. We examine a formulation which is designed to clear its response slowly after irradiation to determine if the formulation is reusable after it clears. If upon reirradiation the dose response remains linear, then reusability is an option. Our results show that the response remains linear over a range of five irradiations and a timespan of two years, but their sensitivity drops around $20 \%$ after the first reirradiation and less than that upon further irradiation. The plastics clear at an exponential rate, but the time it took to clear increased after each reirradiation. These results suggest that a long term reusable dosimeter is possible. Data on a faster clearing formulation will also be presented.
\end{abstract}

Received: 01/31/2020 Accepted: 02/17/2020

Correspondence: Maxwell Recht, Augusta University, $112015^{\text {th }}$ St. Augusta, GA 30912, mrecht@augusta.edu 


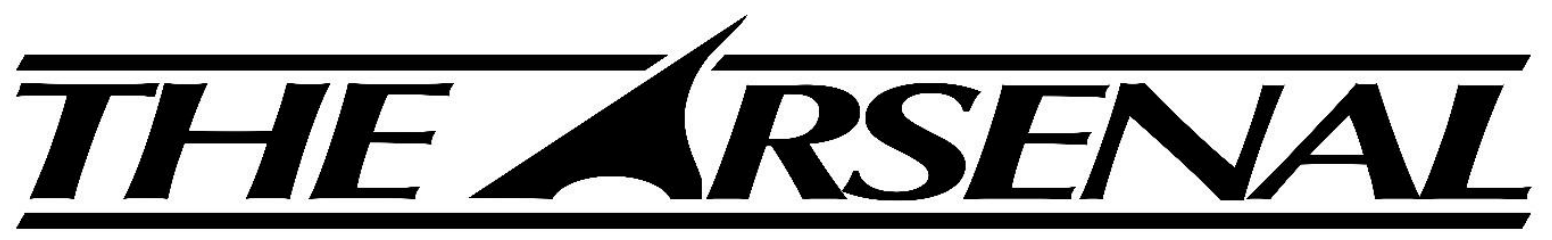

\title{
Augusta University's Undergraduate Research Journal
}

ISSN 2380-5064 | The Arsenal is published by the Augusta University Libraries | http://guides.augusta.edu/arsenal

Volume 3, Issue 2 (2020)

Special Edition Issue

\section{INVESTIGATING SIGNALING PATHWAYS \\ INVOLVING THE HCA RECEPTOR FAMILY}

\author{
Dalia Saj, Najeah Okashah, Angela Spencer, \\ and Nevin Lambert
}

\section{Citation}

Saj, D., Okashah, N., Spencer, A., \& Lambert, N. (2020). Investigating signaling pathways involving the HCA receptor family. The Arsenal: The Undergraduate Research Journal of Augusta University, 3(2), http://doi.org/10.21633/issn.2380.5064/s.2020.03.02.38 


\section{Investigating Signaling Pathways Involving the HCA Receptor Family}

Presenter: Dalia Saj (Poster Presentation)

Authors: Dalia Saj ${ }^{1}$, Najeah Okashah ${ }^{2}$, Angela Spencer ${ }^{3}$, and Nevin Lambert ${ }^{2}$

Faculty Sponsor(s): Angela Spencer, $\mathrm{PhD}$ and Nevin Lambert, $\mathrm{PhD}$

Department Affiliation: ${ }^{1}$ Biology Sciences, ${ }^{2}$ Pharmacology \& Toxicology, ${ }^{3}$ Chemistry \& Physics

Funding: Augusta University CURS Student Research Grant, NIH grant GM130142 to Lambert

\section{ABSTRACT}

Increasing obesity rates have put the American population at higher risk for developing obesity-related medical conditions such as hypertension, heart disease, and diabetes. The hydroxycarboxylic acid (HCA) receptor family is a family of $\mathrm{G}$ protein-coupled receptors (GPCRs) that are expressed in adipose tissue and function as metabolic sensors, making them potential pharmaceutical targets in the treatment of obesity and other metabolic disorders. The HCA receptor family consists of the HCA1, HCA2, and HCA3 receptors, which are activated by hydroxycarboxylic acids such as lactate and 3-hydroxybutyric acid. We utilized bioluminescence resonance energy transfer (BRET) to study agonist-induced coupling of luciferase-tagged HCA receptors to Venus fluorescent protein-tagged G protein heterotrimers or arrestins. Our results indicate that the three HCA receptors couple to the Gi/o subfamily of $\mathrm{G}$ proteins. The data additionally confirms a lack of coupling to the other $\mathrm{G}$ protein subfamilies (Gs, Gq, and G12) and lacks evidence of arrestin recruitment to HCA receptors. Overall, our study highlights the use of BRET as a powerful tool for analysis of GPCR signaling and demonstrates its possible use for future studies to determine the potency of potential drugs targeting HCA receptors as a therapy for healthrelated problems such as obesity.

Received: 01/31/2020 Accepted: 02/17/2020

Correspondence: Dalia Saj, Augusta University, $112015^{\text {th }}$ St. Augusta, GA 30912, dsaj@augusta.edu 


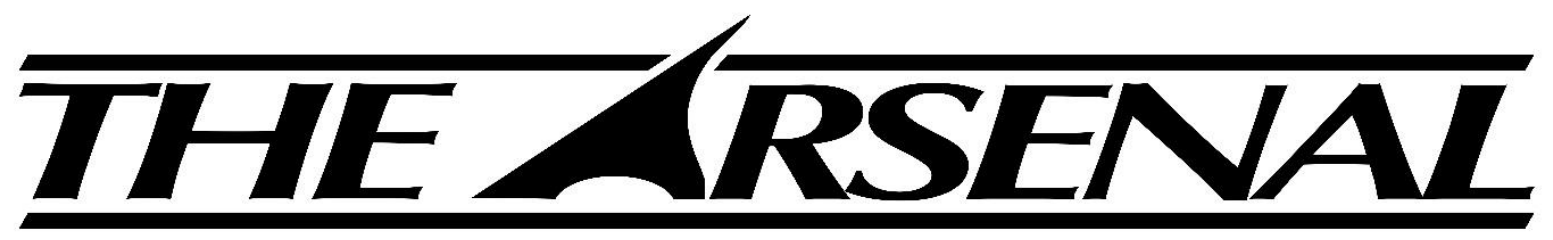

\section{Augusta University's Undergraduate Research Journal}

ISSN 2380-5064 | The Arsenal is published by the Augusta University Libraries | http://guides.augusta.edu/arsenal

Volume 3, Issue 2 (2020)

Special Edition Issue

\section{ASSESSING LOCAL PARKS FOR THEIR INFRASTRUCTURE, ISSUES, AND USE}

Elizabath Shabu and Nicole Peritore

\section{Citation}

Shabu, E., \& Peritore, N. (2020). Assessing local parks for their infrastructure, issues, and use. The Arsenal: The Undergraduate Research Journal of Augusta University, 3(2), http://doi.org/10.21633/issn.2380.5064/s.2020.03.02.39 


\title{
Assessing Local Parks for their Infrastructure, Issues, and Use
}

Presenter: Elizabath Shabu (Poster Presentation)

Authors: Elizabath Shabu and Nicole Peritore

Faculty Sponsor(s): Nicole Peritore, $\mathrm{PhD}$, CHES

Department Affiliation: Kinesiology

\begin{abstract}
This research project assessed public park physical activity infrastructure use in Richmond and Columbia Counties. Prior research has shown that children not only enjoy outdoor time, but also consider parks as a place for socializing. Furthermore, research has shown that playground time positively impacts children's imagination. The playground also aids in the physical fitness of children by offering interactive experiences that can add to the recommended 60 minutes of physical activity a day. Park assessments were conducted utilizing the Physical Activity Resource Assessment (PARA) Tool and found that overall, parks in both counties were well taken care of. Additionally, there was a wide variety of amenities available to utilize. There were some areas of concern in the parks, however, including cigarette buds, alcohol containers, trash, and cracked sidewalks. In both counties, parks were observed to see how much children utilized the playground equipment. Observations concluded that the majority of children utilized the different variety of equipment, with the swings and slides being the most common. In conclusion, this presentation will describe the diversity of amenities, challenges in maintenance, and the overall use of public parks in both Richmond and Columbia Counties.
\end{abstract}

Received: 01/31/2020 Accepted: 02/17/2020

Correspondence: Elizabath Shabu, Augusta University, $112015^{\text {th }}$ St. Augusta, GA 30912, eshabu@augusta.edu 


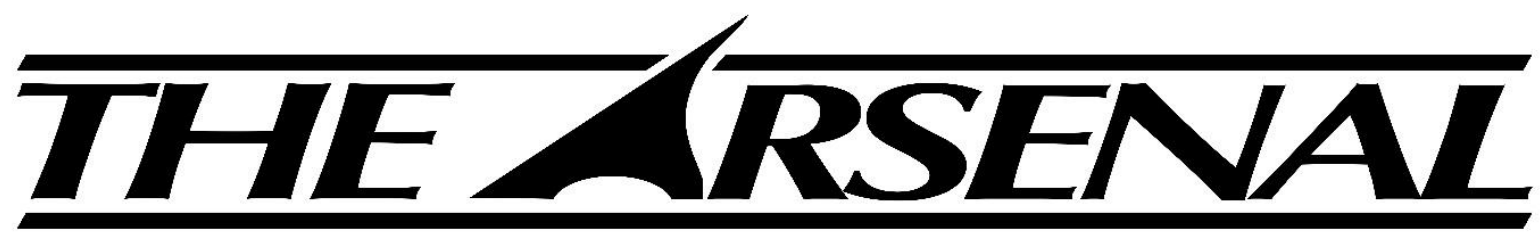

\section{Augusta University's Undergraduate Research Journal}

ISSN 2380-5064 | The Arsenal is published by the Augusta University Libraries | http://guides.augusta.edu/arsenal

Volume 3, Issue 2 (2020)

Special Edition Issue

\section{DEVELOPMENT OF DEFINED CULTURE CONDITIONS FOR HUMAN WHARTON'S JELLY STEM CELLS}

Arika Shaikh and Ali Eroglu

\section{Citation}

Shaikh, A., \& Eroglu, A. (2020). Development of defined culture conditions for human

Wharton's jelly stem cells. The Arsenal: The Undergraduate Research Journal of Augusta

University, 3(2), http://doi.org/10.21633/issn.2380.5064/s.2020.03.02.40 


\title{
Development of Defined Culture Conditions for Human Wharton's Jelly Stem Cells
}

Presenter: Arika Shaikh (Poster Presentation)

Authors: Arika Shaikh ${ }^{1}$ and Ali Eroglu ${ }^{2}$

Faculty Sponsor(s): Ali Eroglu, $\mathrm{PhD}$

Department Affiliation: ${ }^{1}$ Biological Sciences, ${ }^{2}$ Neuroscience \& Regenerative Medicine

\begin{abstract}
Mesenchymal stem cells (MSCs) are multi-potent and capable of differentiating into various cell lineages. While MSCs have commonly been isolated from bone marrow for treatment of numerous diseases, alternative sources including adipose tissue and Wharton's Jelly (WJ), an extra-embryonic umbilical cord tissue rich from hyaluronic acid (HA), are under study for establishment of safer, less invasive procedures. Typically, WJMSCs are cultured in undefined media containing fetal bovine serum, of which use has been associated with different complications, including transmission of infectious agents and induction of immunologic reactions. To facilitate clinical applications, this project aims to develop chemically defined and safe culture conditions for human WJ-MSCs. The hypothesis is that undifferentiated growth of WJ-MSCs will be supported by an HA-based extracellular matrix and fortified DMEM/F12 supplemented with macromolecules, antioxidants, and growth factors. This hypothesis will be tested by comparing the growth kinetics and plasticity of WJ-MSCs cultured under conventional undefined and defined conditions. WJ-MSCs will be isolated via either the "enzymatic digestion" or "tissue explant" methods from human umbilical cords. They will then be phenotyped by evaluating the expression of relevant markers using a MSC phenotyping kit and placed into one of six different culture media groups for experimental testing.
\end{abstract}

Received: 01/31/2020 Accepted: 02/17/2020

Correspondence: Arika Shaikh, Augusta University, $112015^{\text {th }}$ St. Augusta, GA 30912, ashaikh@augusta.edu 


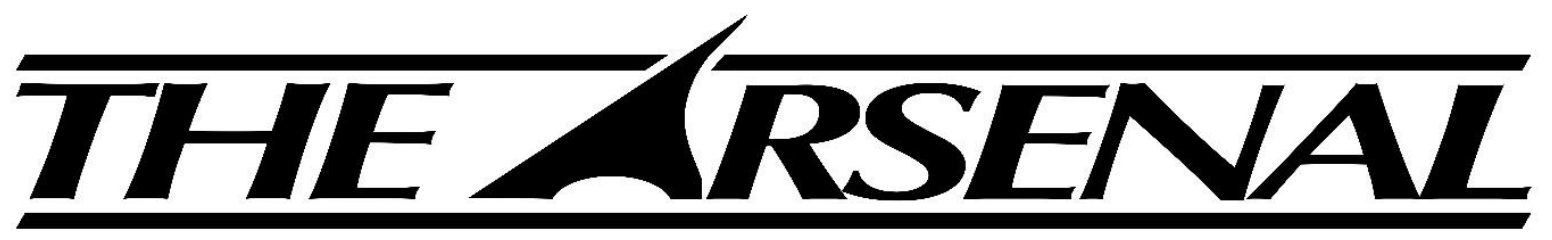

\section{Augusta University's Undergraduate Research Journal}

ISSN 2380-5064 | The Arsenal is published by the Augusta University Libraries | http://guides.augusta.edu/arsenal

Volume 3, Issue 2 (2020)

Special Edition Issue

\section{PORTRAYAL OF MENTAL ILLNESS IN EDGAR ALLAN POE'S “THE TELL-TALE HEART”}

Arika Shaikh and Tim Sadenwasser

\section{Citation}

Shaikh, A., \& Sadenwasser, T. (2020). Portrayal of mental illness in Edgar Allan

Poe's "The Tell-Tale Heart." The Arsenal: The Undergraduate Research Journal

of Augusta University, 3(2), http://doi.org/10.21633/issn.2380.5064/s.2020.03.02.41 


\section{Portrayal of Mental Illness in Edgar Allan Poe's "The Tell-Tale Heart"}

Presenter: Arika Shaikh (Poster Presentation)

Authors: Arika Shaikh ${ }^{1}$ and Tim Sadenwasser ${ }^{2}$

Faculty Sponsor(s): Tim Sadenwasser, $\mathrm{PhD}$

Department Affiliation: ${ }^{1}$ Biological Sciences, ${ }^{2}$ English and Foreign Languages

\section{ABSTRACT}

Edgar Allan Poe's "The-Tell Tale Heart" delves into the human psyche as it entails the story of an unnamed narrator who tells the tale of the murder he commits. Undergoing an emotional rollercoaster of pleasure and guilt, Poe's protagonist maintains his claim to sanity and a sense of reality. Poe articulates many tone and rhythm changes to create a sense of tension, representing the narrator's mental condition. Throughout the narrative, the narrator struggles to reassure that there is nothing wrong and that he is completely normal. Exploring the themes of madness, guilt, and a false sense of reality, Poe's narrator suffers from a sense of false narrative, a trait characteristic of schizophrenia. In addition, the narrator demonstrates episodes of delusions, auditory hallucinations, diminished emotional responses, and significant disturbances to his normal routine which all allude to schizophrenia. I will utilize the Diagnostic and Statistical Manual 5 (DSM-5) criteria, literary criticisms, and other publications to show the audience the schizophrenic nature of Poe's narrator. I will discuss the DSM-5 criteria for schizophrenia and demonstrate how the narrator meets those criteria in several circumstances. Utilizing vivid imagery and a scattered style, Poe explores the mental depths of a man suffering from schizophrenia.

Received: 01/31/2020 Accepted: 02/17/2020

Correspondence: Arika Shaikh, Augusta University, $112015^{\text {th }}$ St. Augusta, GA 30912, ashaikh@augusta.edu 


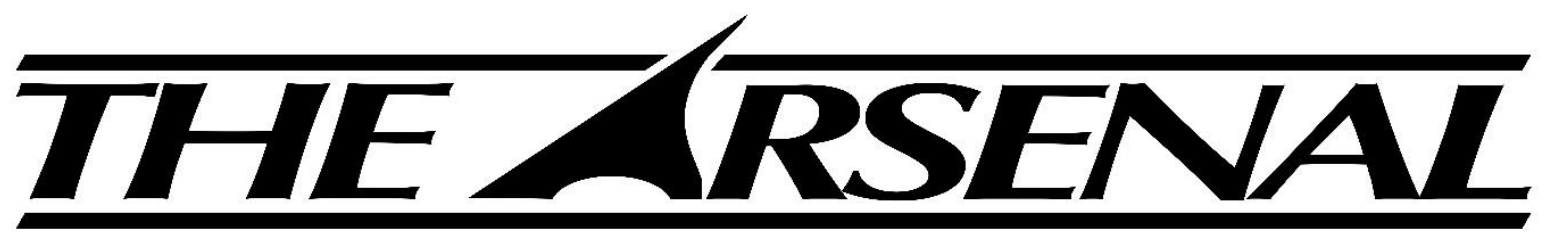

\section{Augusta University's Undergraduate Research Journal}

ISSN 2380-5064 | The Arsenal is published by the Augusta University Libraries | http://guides.augusta.edu/arsenal

Volume 3, Issue 2 (2020)

Special Edition Issue

\section{THE SPACES THEY OCCUPIED: WOMEN AS THE DETERMINERS OF SUCCESS IN THE FRENCH REVOLUTION}

Keturah Stewart and Hubert VanTuyll

\section{Citation}

Stewart, K., \& VanTuyll, H. (2020). The spaces they occupied: Women as the determiners of success in the French Revolution. The Arsenal: The Undergraduate Research Journal of Augusta University, 3(2), http://doi.org/10.21633/issn.2380.5064/s.2020.03.02.42 


\title{
The Spaces They Occupied: Women as the Determiners of Success in the French Revolution
}

Presenter: Keturah Stewart (Oral Presentation)

Authors: Keturah Stewart ${ }^{1}$ and Hubert VanTuyl1 ${ }^{2}$

Faculty Sponsor(s): Hubert VanTuyll, $\mathrm{PhD}$

Department Affiliation: ${ }^{1}$ English and Foreign Languages, ${ }^{2}$ History, Anthropology, \& Philosophy

\begin{abstract}
This presentation examines how during the French Revolution, limited by Enlightenment ideals as to their proper place and sphere, women were forced to participate in means outside the system's framework. Vocally and purposefully excluded from the public sphere, women nevertheless found ways in which to exert influence and actively participate. I contend that the vehement cries for recognition, inclusion, and equality provided a force against which the Revolutionary leaders were critically able to sharpen and strengthen their ideals and movement. The role of counter-revolutionary women is not only important in the amount of agency women were able to obtain and exert on this alternative side, specifically in the realm of religion, but is also of significance for the position it provided in opposition to the movement of Revolutionary women. There is no single moniker or definition one can ascribe to the entirety of women during the period of the French Revolution because there is no single category or demographic, but this presentation will analyze how certain "deviant," "ugly, militant monsters," "ornamental," "helots," and "counter-revolutionaries" made certain the ultimate success of the Revolution, even in its inherent structure against the inclusion of women in the public sphere.
\end{abstract}

Received: 01/31/2020 Accepted: 02/17/2020

Correspondence: Keturah Stewart, Augusta University, $112015^{\text {th }}$ St. Augusta, GA 30912, ketstewart@augusta.edu 


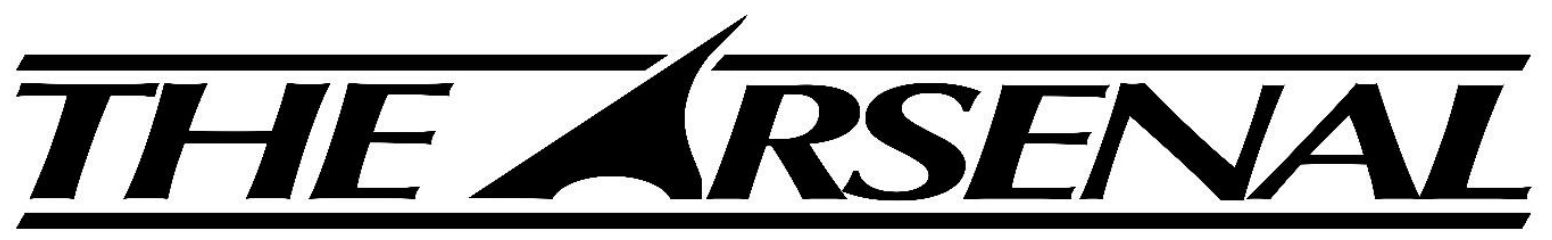

\section{Augusta University's Undergraduate Research Journal}

ISSN 2380-5064 | The Arsenal is published by the Augusta University Libraries | http://guides.augusta.edu/arsenal

Volume 3, Issue 2 (2020)

Special Edition Issue

DESIGN, SYNTHESIS, AND COMPUTATIONAL STUDIES OF ISONIAZID HYBRID CONJUGATES AS POTENTIAL ANTIMYCOBACTERIAL AGENTS

Eyana Thomas and Siva S. Panda

\section{Citation}

Thomas, E., \& Panda, S. S. (2020). Design, synthesis, and computational studies of isoniazid hybrid conjugates as potential antimycobacterial agents.

The Arsenal: The Undergraduate Research Journal of Augusta University, 3(2), http://doi.org/10.21633/issn.2380.5064/s.2020.03.02.43 


\section{Design, Synthesis, and Computational Studies of Isoniazid Hybrid Conjugates as Potential Antimycobacterial Agents}

Presenter: Eyana Thomas (Oral Presentation)

Authors: Eyana Thomas and Siva S. Panda

Faculty Sponsor(s): Siva S. Panda, PhD

Department Affiliation: Chemistry and Physics

Funding: Augusta University CURS Student Research Grant, SPR Translational Research Grant

\section{ABSTRACT}

Tuberculosis (TB) is a bacterial pathogen caused by Mycobacterium tuberculosis, which generally causes pulmonary infection and is extremely pervasive within the lungs and between subjects. Pyrazinamide (PZA) and isoniazid are first-line anti-tuberculosis prodrugs often used in combinational therapy with drugs like ethambutol, streptomycin, and rifampicin. With prolonged administration of the recommended dose, harmful side effects have been reported, such as hepatitis, acute hypertension, thrombocytopenia, and gastrointestinal discomfort. To overcome the problem of toxicity and drug resistance, combination therapy has been used which utilizes the simultaneous administration of two or more antibiotics with independent modes of action and different biochemical targets in the bacteria. Recently, the concept of hybrid molecules has been introduced in anticipation that molecules of this type may overcome drug resistance. This multiple target strategy led to the discovery of various bio-effective hybrid molecules. We have synthesized several pyrazinoic acid hybrid conjugates with isoniazid via amino acid linkers with retention of the chiral integrity of the desired products. All the synthesized compounds were characterized by spectral studies. The details of these studies are presented.

Received: 01/31/2020 Accepted: 02/17/2020

Correspondence: Eyana Thomas, Augusta University, $112015^{\text {th }}$ St. Augusta, GA 30912, eythomas@augusta.edu 


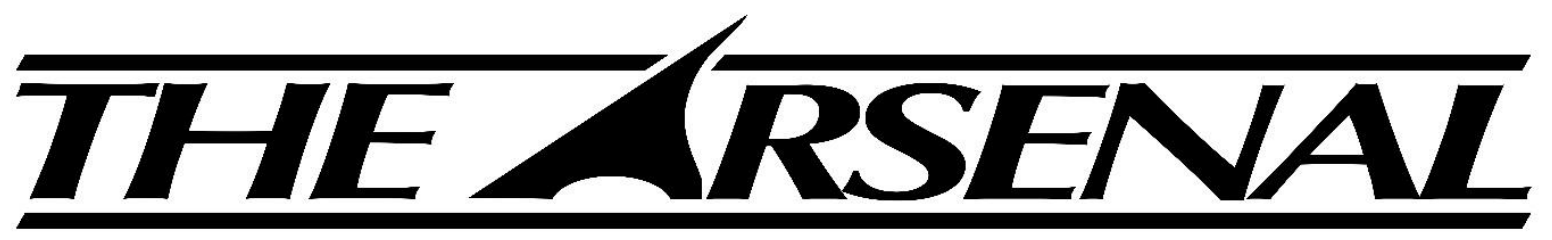

\section{Augusta University's Undergraduate Research Journal}

ISSN 2380-5064 | The Arsenal is published by the Augusta University Libraries | http://guides.augusta.edu/arsenal

Volume 3, Issue 2 (2020)

Special Edition Issue

\section{THE IMPACT OF CARDIAC REHABILITATION ON CVD RISK FACTORS IN DIABETIC PATIENTS}

Eyana Thomas, Eric Lian, Kimberly Roberts, and Lufei Young

\section{Citation}

Thomas, E., Lian, E., Roberts, K., \& Young, L. (2020). The impact of cardiac rehabilitation on CVD risk factors in diabetic patients. The Arsenal:

The Undergraduate Research Journal of Augusta University, 3(2), http://doi.org/10.21633/issn.2380.5064/s.2020.03.02.44 


\title{
The Impact of Cardiac Rehabilitation on CVD Risk Factors in Diabetic Patients
}

Presenter: Eyana Thomas (Poster Presentation)

Authors: Eyana Thomas ${ }^{1}$, Eric Lian $^{2}$, Kimberly Roberts ${ }^{3,4}$, and Lufei Young ${ }^{3}$

Faculty Sponsor(s): Lufei Young, $\mathrm{PhD}$

Department Affiliation: ${ }^{1}$ College of Science and Mathematics, ${ }^{2}$ Medical College of Georgia, ${ }^{3}$ College of Nursing, ${ }^{4}$ Georgia Highlands College

Funding: SPR Translational Research Grant

\begin{abstract}
Patients with diabetes are two to four times more likely to die from cardiac diseases than those without this diagnosis. Cardiac rehabilitation (CR) is known to improve the physical functioning and reduce risk factors in cardiac patients with diabetes. The aim of this study is to evaluate if cardiac patients with comorbidity of diabetes had improved physical functioning (measured by six-minute walk test [6MWT]) and reduced risk factors (measured reduced fasting blood sugar, lipid profile, overweight, fat composition) after the cardiac rehabilitation program. A retrospective observational cohort longitudinal study using secondary data from electronic medical records was conducted. Clinical data were collected from the individual cardiac treatment plan form used by a cardiac rehabilitation center. Among 93 patients, improvement in physical functioning (i.e.: six-minute walk distance) was significant ( $\mathrm{p}$-value $=<.01$ ). This was done by comparing pre and post 6MWT scores.
\end{abstract}

Received: 01/31/2020 Accepted: 02/17/2020

Correspondence: Eyana Thomas, Augusta University, $112015^{\text {th }}$ St. Augusta, GA 30912, eythomas@augusta.edu 


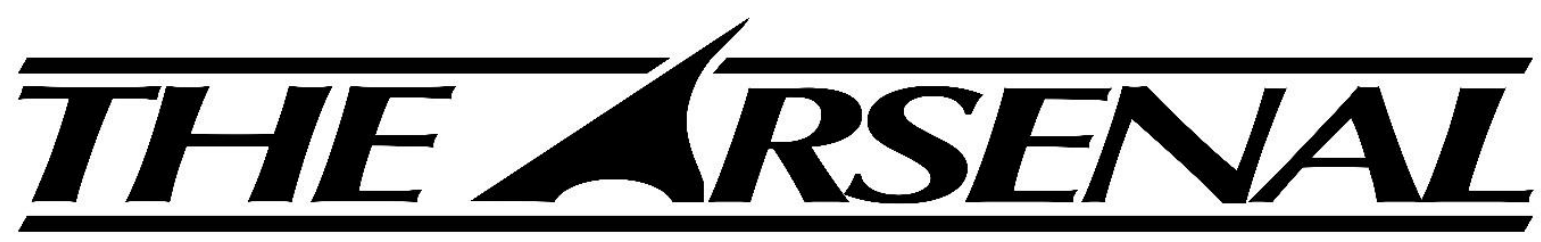

\section{Augusta University's Undergraduate Research Journal}

ISSN 2380-5064 | The Arsenal is published by the Augusta University Libraries | http://guides.augusta.edu/arsenal

Volume 3, Issue 2 (2020)

Special Edition Issue

\section{CURCUMIN CONJUGATES AS POTENTIAL THERAPEUTICS FOR BREAST CANCER}

Queen Tran and Siva S. Panda

\section{Citation}

Tran, Q., \& Panda, S. S. (2020). Curcumin conjugates as potential therapeutics for breast cancer. The Arsenal: The Undergraduate Research Journal of Augusta University, 3(2), http://doi.org/10.21633/issn.2380.5064/s.2020.03.02.45 


\title{
Curcumin Conjugates as Potential Therapeutics for Breast Cancer
}

Presenter: Queen Tran (Oral Presentation)

Authors: Queen Tran and Siva S. Panda

Faculty Sponsor(s): Siva S. Panda, PhD

Department Affiliation: Chemistry and Physics

Funding: Augusta University CURS Student Research Grant

\begin{abstract}
Breast cancer, the target of this study, is one of the most salient forms of cancer in the United States. Among U.S. women, 1 in 8 are diagnosed each year. Current treatment for breast cancer includes dichloroacetic acid (DCA), which is primarily effective at a specific high dosage and leads to side effects such as neuropathy. In a search for an alternative solution with less negative effects, curcumin is studied. Curcumin is a component of turmeric and has an array of health properties, including the alleviation of gastrointestinal complications and certain pulmonary diseases, and the inhibition of cancer growth. However, curcumin's main drawback lies in its low bioavailability, thus allowing little to be absorbed into the body upon ingestion. The objective of this study was to design the synthesis for the improvement of DCA as well as increase the bioavailability of curcumin by conjugating the two components with an amino acid linker in between DCA and curcumin. Prior to synthesis of the amino acid-linked hybrid conjugates, the preceding procedures are standardized. Upon conjugation, it is anticipated that the overall bioavailability will increase, and the effective dosage will decrease, resulting in a potentially more effective breast cancer treatment. The final synthesized compounds will then be analyzed and subsequently studied in breast cancer line cells and animal tests.
\end{abstract}

Received: 01/31/2020 Accepted: 02/17/2020

Correspondence: Queen Tran, Augusta University, $112015^{\text {th }}$ St. Augusta, GA 30912, quetran@augusta.edu 


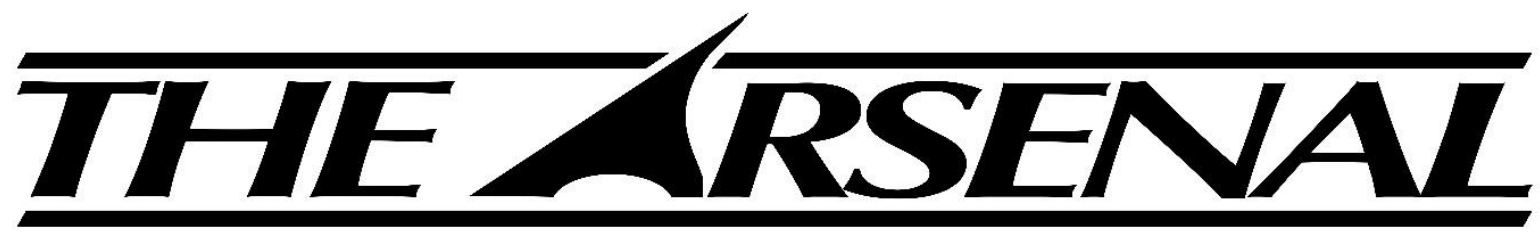

Augusta University's Undergraduate Research Journal

ISSN 2380-5064 | The Arsenal is published by the Augusta University Libraries | http://guides.augusta.edu/arsenal

Volume 3, Issue 2 (2020)

Special Edition Issue

THE PAST IS A FOREIGN COUNTRY THEY VIEW

THINGS DIFFERENTLY THERE: THE PERCEPTION

OF "THE INVISIBLE EMPIRE OF THE KU KLUX KLAN"

AS A BENEVOLENT SECRET SOCIETY FROM 1915 TO 1965

Dillon Typhair and Ruth McClelland-Nugent

\section{Citation}

Typhair, D., \& McClelland-Nugent, R. (2020). The past is a foreign country they view things differently there: The perception of "The Invisible Empire of the Ku Klux Klan" as a benevolent secret society from 1915 to 1965. The Arsenal: The Undergraduate Research Journal of Augusta University, 3(2), http://doi.org/10.21633/issn.2380.5064/s.2020.03.02.46

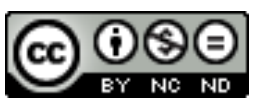

(C) Typhair and McClelland-Nugent 2020. This open access article is distributed under a Creative Commons Attribution NonCommercial-NoDerivs 2.0 Generic License (https://creativecommons.org/licenses/by-nc-nd/2.0/). 


\section{The Past is a Foreign Country They View Things Differently There: The Perception of "The Invisible Empire of the Ku Klux Klan" as a Benevolent Secret Society from 1915 to 1965}

Presenter: Dillon Typhair (Poster Presentation)

Authors: Dillon Typhair and Ruth McClelland-Nugent

Faculty Sponsor(s): Ruth McClelland-Nugent, $\mathrm{PhD}$

Department Affiliation: History, Anthropology, \& Philosophy

\section{ABSTRACT}

This presentation looks at the history of Americans' changing attitudes toward the $\mathrm{Ku}$ Klux Klan, and contributes to the scholarship on Civil War history and domestic terrorism through the case of the KKK. The journalist Edward Pollard's book, The Lost Cause: A New Southern History of the War of the Confederates (1867), influenced generations of Americans both south and north by writing a revisionist history of the Civil War, painting confederates as rebels who should still fight to maintain white supremacy. The belief in this "lost cause" led many Americans, in the south especially, to support and have positive attitudes toward the KKK. However, even as the Klan claimed to support the ideals of the "lost cause," their actions often undermined their claims of benevolence and of upholding southern value. The Klan, especially after its revival post-WWI, terrorized anyone they deemed not "pure American" through violent acts. Today, it is unlikely that the Klan will ever be positively regarded as it once was, even if similar hate groups still plague society. 


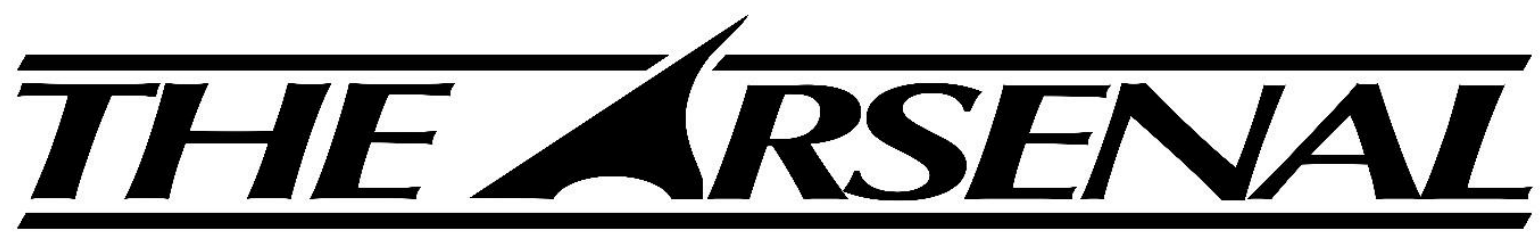

\section{Augusta University's Undergraduate Research Journal}

ISSN 2380-5064 | The Arsenal is published by the Augusta University Libraries | http://guides.augusta.edu/arsenal

Volume 3, Issue 2 (2020)

Special Edition Issue

\section{GIVE RISE}

\section{Rachel M. Visintainer and Melanie O'Meara}

\section{Citation}

Visintainer, R. M., \& O’Meara, M. (2020). Give rise. The Arsenal:

The Undergraduate Research Journal of Augusta University, 3(2), http://doi.org/10.21633/issn.2380.5064/s.2020.03.02.47 


\title{
Give Rise
}

Presenter: Rachel M. Visintainer (Oral Presentation)

Authors: Rachel M. Visintainer and Melanie O'Meara

Faculty Sponsor(s): Melanie O'Meara, $\mathrm{PhD}$

Department Affiliation: Communications

Funding: Augusta University CURS Summer Scholars Program, Pamplin Student Research \& Travel Grant

\begin{abstract}
"Give rise to magic / now. Tear off the mask, create! / Create now, or die." For my Voice \& Movement class in Fall 2019, I wrote and performed an extended version of this haiku titled "Give Rise." In "Give Rise," I implement Grotowski's five focuses of breath, phonation, resonance, articulation, and thought, as well as my posture and physical placement in the room, in order to portray different characters. Building the performance was a process. In my initial writing, I was inspired by Grotowski's concept of starting from the roots of our being and abandoning all social identities or markers ("masks") when acting. I intended to portray the urgency and spontaneity behind creating art with abandon. Upon further thought, the phrase "create now or die" bothered me. I found myself reflecting on the meaning behind such a demand. Ultimately, "Give Rise" embodies a brief exploration of mental health and its relationship with producing art. My haiku performance became a critique of my own haiku. While I have my own method behind my performance choices, these choices intend to make room for personal interpretation.
\end{abstract}

Received: 01/31/2020 Accepted: 02/17/2020

Correspondence: Rachel M. Visintainer, Augusta University, 1120 15 ${ }^{\text {th }}$ St. Augusta, GA 30912, ravisintainer@augusta.edu 


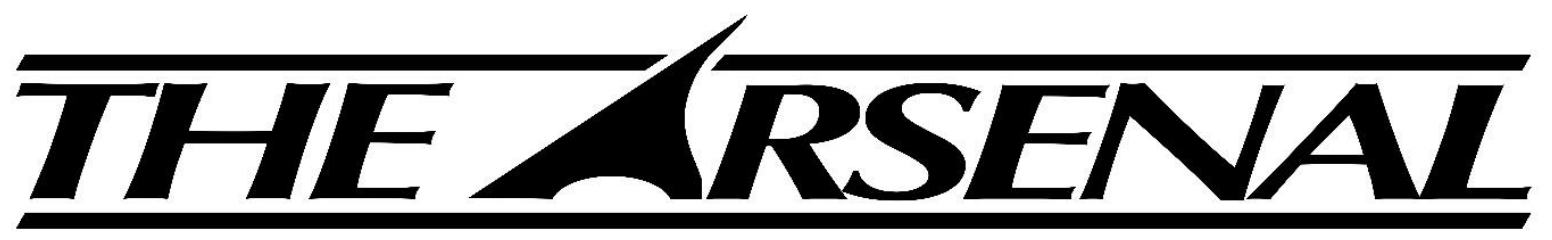

\section{Augusta University's Undergraduate Research Journal}

ISSN 2380-5064 | The Arsenal is published by the Augusta University Libraries | http://guides.augusta.edu/arsenal

Volume 3, Issue 2 (2020)

Special Edition Issue

DESIGN AND SYNTHESIS OF SELECTIVE

COX-2 INHIBITORS AS POTENTIAL

ANTI-INFLAMMATORY AGENTS

Margaret Wade and Siva S. Panda

\section{Citation}

Wade, M., \& Panda, S. S. (2020). Design and synthesis of selective COX-2 inhibitors as potential anti-inflammatory agents. The Arsenal: The Undergraduate Research Journal of Augusta University, 3(2), http://doi.org/10.21633/issn.2380.5064/s.2020.03.02.48

(C) Wade and Panda 2020. This open access article is distributed under a Creative Commons Attribution NonCommercial-NoDerivs 2.0 Generic License

(https://creativecommons.org/licenses/by-nc-nd/2.0/). 


\title{
Design and Synthesis of Selective COX-2 Inhibitors as Potential Anti-Inflammatory Agents
}

Presenter: Margaret Wade (Oral Presentation)

Authors: Margaret Wade and Siva S. Panda

Faculty Sponsor(s): Siva S. Panda, PhD

Department Affiliation: Chemistry and Physics

Funding: Augusta University CURS Summer Scholars Program

\begin{abstract}
Inflammation is a common immune response to harmful pathogens or damaged cells. Nonsteroidal anti-inflammatory drugs (NSAIDs) are commonly used to treat inflammation as they inhibit the cyclooxygenase enzyme systems (COX). Selectivity for inhibition of the COX-2 pathway is an aim in the development of NSAIDs, as their adverse side effects are associated with the inhibition of the COX-1 pathway. We have designed and synthesized several hybrid conjugates of ibuprofen with various amino acid linkers showing promising anti-inflammatory properties and decreased gastric ulcer formation. The current developing new hybrid conjugates are based on the rational drug design process.
\end{abstract}

Received: 01/31/2020 Accepted: 02/17/2020

Correspondence: Margaret Wade, Augusta University, $112015^{\text {th }}$ St. Augusta, GA 30912, mwade3@augusta.edu 


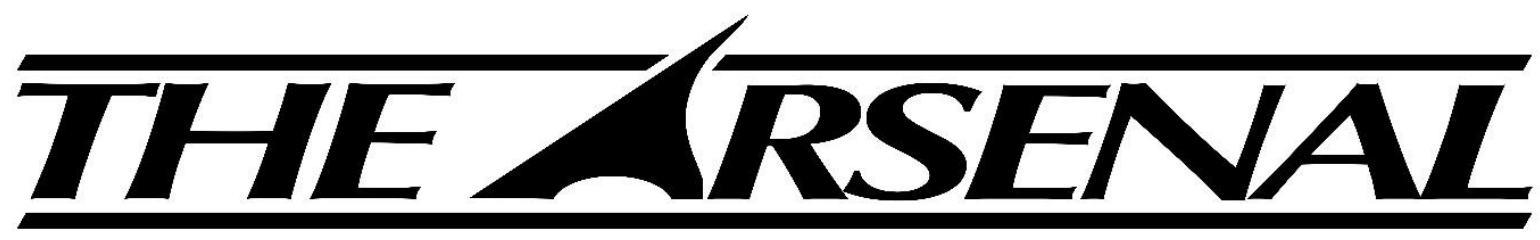

\section{Augusta University's Undergraduate Research Journal}

ISSN 2380-5064 | The Arsenal is published by the Augusta University Libraries | http://guides.augusta.edu/arsenal

Volume 3, Issue 2 (2020)

Special Edition Issue

\section{HOW DOES INDUSTRIAL CONCENTRATION PREPARE AN ECONOMY FOR BUSINESS CYCLE CHANGE?}

\section{Aaron Walker and Simon Medcalfe}

\section{Citation}

Walker, A., \& Medcalfe, S. (2020). How does industrial concentration prepare an economy for business cycle change? The Arsenal: The Undergraduate Research

Journal of Augusta University, 3(2), http://doi.org/10.21633/issn.2380.5064/s.2020.03.02.49 


\title{
How Does Industrial Concentration Prepare an Economy for Business Cycle Change?
}

Presenter: Aaron Walker (Oral Presentation)

Authors: Aaron Walker and Simon Medcalfe

Faculty Sponsor(s): Simon Medcalfe, $\mathrm{PhD}$

Department Affiliation: Business

\begin{abstract}
This analysis will examine the relationship between the business cycle and industry concentrations across Georgia and South Carolina, with employment being the industry measurement of concentration. The concentration measure will be the HerfindahlHirschman Index (HHI). Although typically used to determine market concentration within an industry, this analysis will utilize the HHI to calculate the concentration levels across different industries within the Metropolitan Statistical Areas (MSAs) of Georgia and South Carolina. Data will be collected from 2004 through 2016 to include prominent business cycle periods. It is hypothesized that highly concentrated MSAs will suffer the impact of recession periods, more than less concentrated MSAs. This research will inform the workforce, residents, and policymakers, of Georgia-South Carolina, with a better understanding of the impact of recessions on their local communities
\end{abstract}

Received: 01/31/2020 Accepted: 02/17/2020

Correspondence: Aaron Walker, Augusta University, $112015^{\text {th }}$ St. Augusta, GA 30912, aawalker@augusta.edu 


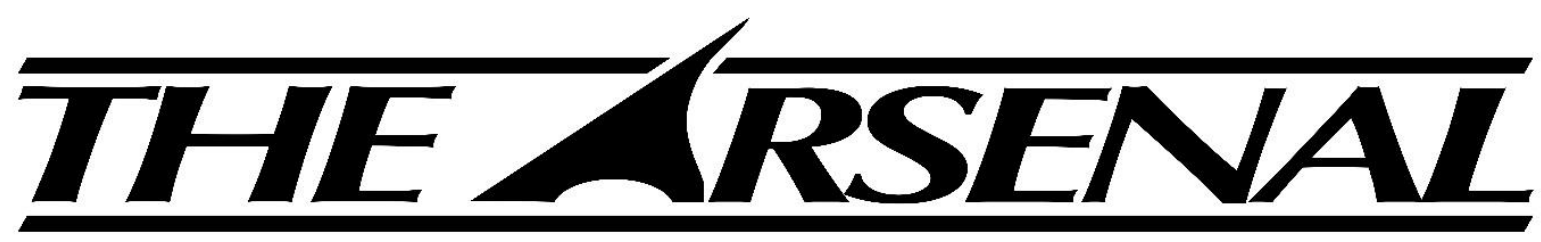

\section{Augusta University's Undergraduate Research Journal}

ISSN 2380-5064 | The Arsenal is published by the Augusta University Libraries | http://guides.augusta.edu/arsenal

Volume 3, Issue 2 (2020)

Special Edition Issue

\section{ATYPICAL MAGNESIUM REQUIREMENTS IN A PHYLLITE POPULATION OF RARE PLANT SPECIES, PEDIOMELUM PIEDMONTATUM}

\section{Matthew Zimmerman and Stacy Bennetts}

\section{Citation}

Zimmerman, M., \& Bennetts, S. (2020). Atypical magnesium requirements in a phyllite population of rare plant species, pediomedlum piedmontatum. The Arsenal:

The Undergraduate Research Journal of Augusta University, 3(2), http://doi.org/10.21633/issn.2380.5064/s.2020.03.02.50 


\title{
Atypical Magnesium Requirements in a Phyllite Population of Rare Plant Species, Pediomelum Piedmontatum
}

Presenter: Matthew Zimmerman (Oral Presentation)

Authors: Matthew Zimmerman and Stacy Bennetts

Faculty Sponsor(s): Stacy Bennetts, $\mathrm{PhD}$

Department Affiliation: Biological Sciences

\begin{abstract}
Pediomelum piedmontatum, Dixie Mt. Breadroot, is a rare legume species that was discovered in 2006. Currently, there are only three known populations, which are growing in either serpentine or phyllite soil. Both soil types contain extremely high concentrations of magnesium $(\mathrm{Mg})$ as well as other heavy metals. Previous experiments have revealed that propagation of $P$. piedmontanum is unsuccessful in potting soil, with high levels of mortality approximately two months after germination. Since $\mathrm{Mg}$ is unusually high in both soil types, it was hypothesized that survivability and growth of seedlings would be greater with $\mathrm{Mg}$-enriched soil than in potting soil. In order to test this hypothesis, seedlings from a phyllite population ( 7 plants/pot with 3 replicate pots/Mg group and 2 pots/control) were transplanted into one of the following potting soil enrichments: $50 \mu \mathrm{M}$ MgSO4, $100 \mu \mathrm{M} \mathrm{MgSO}$, or controls with no Mg enrichment. During 12 weeks, seedlings in $100 \mu \mathrm{M} \mathrm{Mg}$ displayed the greatest survivability and shoot growth, with the lowest survivability in control pots. Atypical $\mathrm{Mg}$ requirements have been noted in the literature for some plants adapted to serpentine soil, but this is a unique discovery for a population adapted to phyllite.
\end{abstract}

Received: 01/31/2020 Accepted: 02/17/2020

Correspondence: Matthew Zimmerman, Augusta University, $112015^{\text {th }}$ St. Augusta, GA 30912, matzimmerman@augusta.edu 